\title{
Simple models for the simulation of submarine melt for a Greenland glacial system model
}

\author{
Johanna Beckmann, Mahé Perrette, and Andrey Ganopolski \\ Earth System Analysis - Research Domain 1, Potsdam Institute for Climate Impact Research, 14412 Potsdam, Germany \\ Correspondence: Johanna Beckmannn (beckmann@pik-potsdam.de)
}

Received: 14 December 2016 - Discussion started: 4 January 2017

Revised: 9 November 2017 - Accepted: 27 November 2017 - Published: 26 January 2018

\begin{abstract}
Two hundred marine-terminating Greenland outlet glaciers deliver more than half of the annually accumulated ice into the ocean and have played an important role in the Greenland ice sheet mass loss observed since the mid1990s. Submarine melt may play a crucial role in the mass balance and position of the grounding line of these outlet glaciers. As the ocean warms, it is expected that submarine melt will increase, potentially driving outlet glaciers retreat and contributing to sea level rise. Projections of the future contribution of outlet glaciers to sea level rise are hampered by the necessity to use models with extremely high resolution of the order of a few hundred meters. That requirement in not only demanded when modeling outlet glaciers as a stand alone model but also when coupling them with highresolution 3-D ocean models. In addition, fjord bathymetry data are mostly missing or inaccurate (errors of several hundreds of meters), which questions the benefit of using computationally expensive 3-D models for future predictions. Here we propose an alternative approach built on the use of a computationally efficient simple model of submarine melt based on turbulent plume theory. We show that such a simple model is in reasonable agreement with several available modeling studies. We performed a suite of experiments to analyze sensitivity of these simple models to model parameters and climate characteristics. We found that the computationally cheap plume model demonstrates qualitatively similar behavior as 3-D general circulation models. To match results of the 3-D models in a quantitative manner, a scaling factor of the order of 1 is needed for the plume models. We applied this approach to model submarine melt for six representative Greenland glaciers and found that the application of a line plume can produce submarine melt compatible with observational data. Our results show that the line plume model is
\end{abstract}

more appropriate than the cone plume model for simulating the average submarine melting of real glaciers in Greenland.

\section{Introduction}

Since the 1990s the decadal loss of ice mass by the Greenland ice sheet (GrIS) has quadrupled (Straneo and Heimbach, 2013), with an average 1993-2010 contribution of $0.33 \pm 0.08 \mathrm{~mm} \mathrm{yr}^{-1}$, which is about $10 \%$ of the observed sea level rise during this period (Church and White, 2011; Church et al., 2013). This acceleration of the GrIS mass loss is attributed to increase of surface melt due to atmospheric warming (Khan et al., 2014) and speedup of the marine-terminating outlet glaciers (Rignot and Kanagaratnam, 2006). The latter has been connected, among other factors, to enhanced submarine melting, which in turn is caused by warming of the surrounding ocean (Straneo et al., 2012) and, probably, by increased subglacial water discharge (Straneo and Heimbach, 2013). While ice-ocean interaction potentially plays an important role in recent and future mass balance changes of the GrIS, the understanding of this interaction remains rather poor and represents one of the main source of the uncertainties in future sea level rise projection (Church et al., 2013). The ice sheet models used for the study of GrIS response to global warming and its contribution to sea level rise typically have resolution of 5 to $10 \mathrm{~km}$ (Bindschadler et al., 2013), which is too coarse to resolve most Greenland outlet glaciers. Instead, regional modeling at higher resolution is better suited to capture glacier dynamics. As an alternative to costly three-dimensional models, one-dimensional flow line models were convincingly applied to several major outlet glaciers (Nick et al., 2012, 2013; 
Lea et al., 2014; Carr et al., 2015). In particular, Nick et al. (2012) simulated with a flow line model the dynamical response of the Petermann Glacier to the abrupt breakup of its floating tongue in 2010 and investigated the influence of increased submarine melting on future stability of the glacier. They demonstrated the strong influence of increased submarine melt rate to the glacier's mass loss. In this study, submarine melt rate was prescribed and held constant. Using the same flow line model, Nick et al. (2013) implemented submarine melt proportional to the ocean temperature outside of the fjord. This study was performed for the four largest outlet glaciers. Under the assumption that the result of the four largest glaciers can be scaled up for the remaining glaciers, Nick et al. (2013) estimate a total contribution of the Greenland outlet glaciers to global sea level rise of up to $5 \mathrm{~cm}$ during the $21 \mathrm{st}$ century or about $50 \%$ of the maximum expected GrIS contribution due to changes in surface mass balance. For the same period of time but using a three-dimensional ice sheet model, Fürst et al. (2015) estimated the contribution of enhanced ice discharge through outlet glaciers to be 20 to $40 \%$ of the total mass loss. These large uncertainties are associated, among other factors, with the parameterization of the submarine melt rate. Note that in Fürst et al. (2015) the effect of ocean warming was parameterized through enhanced basal sliding rather than explicit treatment of submarine melt. Different approaches have been taken to estimate submarine melt rates of outlet glaciers by using empirical data (Motyka et al., 2013; Rignot et al., 2010): simplified one-dimensional models of line plumes (Jenkins, 1991, 2011), axisymmetric plume models (Cowton et al., 2015; Turner, 1973) and numerical two- and threedimensional ocean models (Holland et al., 2007; Little et al., 2009; Sciascia et al., 2013; Xu et al., 2013; Slater et al., 2015). Note that 2-D and 3-D modeling efforts also differ with respect to model formulation, in particular some authors use hydrostatic models (e.g., Holland et al., 2008; Little et al., 2009), while others use nonhydrostatic models (e.g., Sciascia et al., 2013). The experiments studied submarine melt with respect to subglacial discharge and its spatial pattern and vertical ocean temperature and salinity profiles. Additionally, the influence of subglacial discharge on the fjord circulation, which connects outlet glaciers with the surrounding ocean, was investigated with 3-D models (Cowton et al., 2015; Carroll et al., 2015). Different authors considered two main types of subglacial discharge. The first one is uniformly distributed along the grounding line (referred hereafter as "line plume", LP) (Jenkins, 1991, 2011; Sciascia et al., 2013; Slater et al., 2015; Xu et al., 2012) while the second one has localized subglacial discharge (the axisymmetric plume, referred hereafter as "cone plume", CP) (Cowton et al., 2015; Turner, 1973; Slater et al., 2015; Xu et al., 2013). The CP approach is motivated by the observation that a significant fraction of subglacial discharge during the melt season emerges through one or several channels underneath the glacier (Rignot et al., 2015; Stevens et al., 2016;
Sole et al., 2011). All of the above-mentioned 2-D and 3-D model simulations show, in agreement with previous theoretical studies, that submarine melt strongly depends both on the ambient water temperature and the magnitude of subglacial discharge. However, different modeling studies revealed the complex dependence of submarine melting on temperature. Sciascia et al. (2013) investigated tidewater glaciers and found a linear dependence of the submarine melt rate on ambient water temperature above freezing point. In contrast, Holland et al. (2008) and Little et al. (2009) found a quadratic dependence on temperature under large ice shelves. Xu et al. (2013) detected that this relationship of melt rate to thermal forcing depends on the amount of subglacial discharge released through a single channel at a tidewater glacier: the melt rate dependence to temperature has a power of 1.76 for small discharges and is lower for higher discharge. Slater et al. (2016) found a power law dependence of melt rate on discharge, with the exponent $1 / 3$ for both the $\mathrm{CP}$ and the LP models in a uniform stratification. For a linear stratification their study shows that the exponent enlarges to $3 / 4$ for the CP model and to $2 / 3$ for the LP model. A change in power law could also be detected by Xu et al. (2013). They determined an exponent of 0.5 at high discharge and 0.85 at low discharge for the CP. Simulations with 3-D models show the strong dependency of CP melt rate on stratification or other environmental factors, with maximum melt rate near the surface (e.g., Kimura et al., 2014, unstratified) or close to the bottom (e.g., Slater et al., 2015; Xu et al., 2013, stratified). While experiments with high-resolution (several to $10 \mathrm{~m}$ ) nonhydrostatic 3-D ocean models demonstrate their potential to simulate rather realistically turbulent plumes and melt rates of marine-based glaciers, such models are too computationally expensive for modeling of the entire Greenland glacial system response to climate change on centennial timescale. An alternative is to use a method for submarine melt based on a simplified plume model (Jenkins, 2011; Cowton et al., 2015). Such a plume model can then be used to calculate submarine melt in, e.g., 1-D ice stream models. This would represent a step forward compared to a rather simplistic treatment of submarine melt used in previous works (e.g., Nick et al., 2013). The main purpose of this paper is to investigate the applicability of the simple plume models to simulation of melt rate of real glaciers in Greenland. To this end we first compared both cone and linear plume models with the available results of simulations from high-resolution 3-D ocean models. Then we compare results of plume models with the empirical estimates of submarine melt from several Greenland glaciers. The paper is organized as follows. The two versions of plume model are described in Sect. 2. We then study the plume model's sensitivity of simulated submarine melt rate to ocean temperature and salinity, the amount of subglacial discharge and the geometry of the calving front of the glacier itself. Results of simulations with the simple plume models are compared to results of numerical experiments with 3-D and 2-D ocean models in Sect. 4. 
In Sect. 5 we compare our simulations to empirically estimated submarine melt rates for several selected Greenland glaciers. Finally, in Sect. 6 we discuss the applicability of the plume model for the purpose of developing a comprehensive Greenland glacial system model.

\section{The plume models}

A plume model describes buoyancy-driven rise of subglacial meltwater after it exits subglacial channels, until it reaches neutral buoyancy near the surface. Two counteracting processes control its evolution: (a) submarine melting of the ice-ocean interface under the floating tongue (if any) and upwards along the calving front and (b) turbulent entrainment and mixing of surrounding fjord water. These processes act to maintain or reduce plume buoyancy, respectively. Subglacial meltwater discharge $Q_{\mathrm{sg}}$ for a glacier can be estimated from surface runoff and basal melt over the catchment area of the glacier. How this discharge is distributed along the grounding line, however, is in general not known. It is believed that at least during the summer season, most of the subglacial discharge occurs through a network of channels (Chauche, 2016; Rignot and Steffen, 2008; Rignot et al., 2015; Schoof, 2010) but their precise number for different glaciers and relative importance is not known and can change throughout the season. We investigate two situations. The LP model corresponds to the simplest assumption that $Q_{\text {sg }}$ is uniformly distributed along the grounding line (Fig. 1a), while the $\mathrm{CP}$ assumes point-wise release of meltwater (Fig. 1b), i.e., from a channel whose dimensions are small compared to the plume diameter. Furthermore, the CP model assumes that a self-similar half-conical form is maintained. Note that there can be a number of discretely distributed plumes along the glacier, implying numerous CPs.

\subsection{Model equations}

Both models are formulated in one dimension, $x$, which is the distance from the grounding line upwards along the glacier front, or under the ice shelf, and depends on the glacier shape, described by its slope $\alpha$ (Fig. 1). The model equations are written under the assumption that the plume is in equilibrium and therefore do not explicitly account for time. All model parameters and their descriptions are listed in Table 1.

\subsubsection{Line plume}

The LP model after Jenkins (2011) accounts for a uniformly distributed subglacial discharge along the grounding line of a glacier (Fig. 1a). Far enough from the lateral boundaries, it assumes invariance by translation along the grounding line, so that the resulting equations only depend on $x$ with $\frac{\mathrm{d}()}{\mathrm{d} x}=$ ()':

$q^{\prime}=\dot{e}+\dot{m}$, (a)

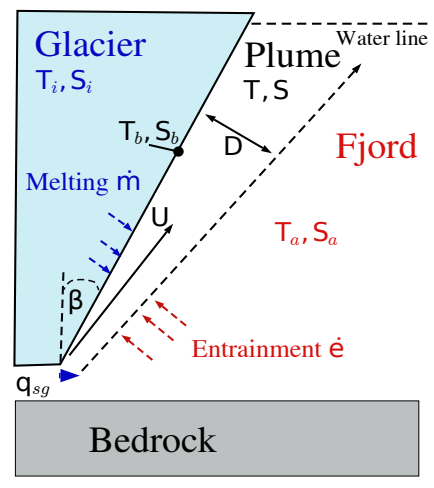

(b)

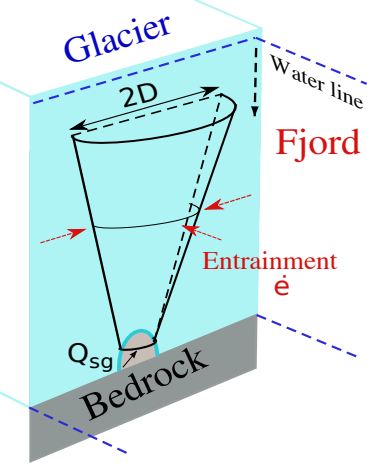

Figure 1. (a) Conceptual scheme of the 1-D plume model after Jenkins (2011). Subglacial freshwater flux $q_{\mathrm{sg}}$, which is uniformly distributed along the grounding line, enters the fjord, where it forms a plume that rises up due to buoyancy. The plume is described explicitly with its temperature $T$, salinity $S$, thickness $D$ and velocity $U$. It rises along the ice shelf, following the shelf's slope $\alpha=90^{\circ}-\beta$, until it either reaches the water surface or has zero velocity due to the loss of buoyancy. The ambient water with salinity $S_{\mathrm{a}}$ and temperature $T_{\mathrm{a}}$ entrains into the plume with entrainment rate $\dot{e}$. Melting $(\dot{m})$ occurs on the glacier front and adds to the plume buoyancy with water of the temperature $T_{\mathrm{b}}$ and salinity $S_{\mathrm{b}}$. (b) Conceptual scheme of two-dimensional CP model modified after Jenkins (1991) and Cowton et al. (2015). Subglacial discharge enters the fjord, localized via a channel. The plume geometry is described as a half cone and the entrainment occurs around the arc. The subglacial discharge is $Q_{\mathrm{sg}}=\frac{D_{0}^{2} U_{0} \pi}{2}$, where $D_{0}$ is the initial radius and $U_{0}$ is the initial velocity.

$$
\begin{aligned}
& (q U)^{\prime}=D \frac{\Delta \rho}{\rho_{0}} g \sin (\alpha)-C_{\mathrm{d}} U^{2}, \\
& (q T)^{\prime}=\dot{e} T_{\mathrm{a}}+\dot{m} T_{\mathrm{b}}-C_{\mathrm{d}}^{\frac{1}{2}} U \Gamma_{T}\left(T-T_{\mathrm{b}}\right), \\
& (q S)^{\prime}=\dot{e} S_{\mathrm{a}}+\dot{m} S_{\mathrm{b}}-C_{\mathrm{d}}^{\frac{1}{2}} U \Gamma_{S}\left(S-S_{\mathrm{b}}\right),
\end{aligned}
$$

where the plume state variables $D, U, T$ and $S$ stand for its thickness, velocity in the $x$ direction, temperature and salinity, respectively, all dependent on $x$. Equation (1) describes the conservation of volume flux $q=D U$ (expressed per unit length in the lateral direction, i.e., $\mathrm{m}^{2} \mathrm{~s}^{-1}$ ), which can increase by the entrainment of ambient seawater $\dot{e}$ and by melting $\dot{m}$ of ice from the glacier front. The momentum flux (Eq. 2) is based on the balance between buoyancy flux and the drag $C_{\mathrm{d}} U^{2}$ of the glacier front. The buoyancy flux is proportional to the relative density contrast $\frac{\Delta \rho}{\rho_{0}}$ between plume water and ambient water in the fjord (subscript a), parameterized in linear form as $\beta_{S}\left(S_{\mathrm{a}}-S\right)-\beta_{T}\left(T_{\mathrm{a}}-T\right)$, with coefficient $\beta_{S}$ and $\beta_{T}$ indicated in Table 1. The drag also results in a turbulent boundary layer (subscript b) at the icewater interface, where melting occurs, and heat and salt is exchanged by (turbulent) conduction-diffusion. The equations for $T$ and $S$ (Eqs. 3, 4) account for the entrainment of ambient water and the addition of meltwater as well as for 
Table 1. Model parameters of the LP and CP model with typical fjord default values. Note that the values may differ for specific experiments (as explicitly stated in the corresponding descriptions).

\begin{tabular}{lrll}
\hline Symbol & Value & Units & Description \\
\hline$q_{\mathrm{sg}}$ & 0.1 & $\mathrm{~m}^{2} \mathrm{~s}^{-1}$ & default value for subglacial discharge for LP \\
$Q_{\mathrm{sg}}$ & 500 & $\mathrm{~m}^{3} \mathrm{~s}^{-1}$ & default value for subglacial discharge for CP \\
$U_{\star 0}$ & - & $\mathrm{m} \mathrm{s}^{-1}$ & initial default value for plume velocity \\
$\left.T\right|_{x 0}$ & 0 & ${ }^{\circ} \mathrm{C}$ & initial default value for plume temperature \\
$T_{\mathrm{a}}$ & 4 & ${ }^{\circ} \mathrm{C}$ & default value for ambient temperature \\
$T_{\mathrm{i}}$ & -10 & ${ }^{\circ} \mathrm{C}$ & default value inner ice temperature \\
$S_{x 0}$ & $1 \times 10^{-6}$ & $\mathrm{psu}$ & default value for ambient salinity \\
$S_{\mathrm{a}}$ & 34.65 & $\mathrm{psu}$ & default value for ambient salinity \\
$S_{\mathrm{i}}$ & 0 & $\mathrm{psu}$ & default value for inner ice salinity \\
$E_{0}$ & $0.1[0.036-0.16]$ & - & entrainment coefficient \\
$C_{\mathrm{d}}$ & $2.5 \times 10^{-3}$ & - & drag coefficient \\
$\lambda_{1}$ & $-5.73 \times 10^{-2}$ & ${ }^{\circ} \mathrm{C}$ & seawater freezing point slope \\
$\lambda_{2}$ & $8.32 \times 10^{-2}$ & ${ }^{\circ} \mathrm{C}$ & seawater freezing point offset \\
$\lambda_{3}$ & $7.61 \times 10^{-4}$ & ${ }^{\circ} \mathrm{C} \mathrm{m}-1$ & depth dependence of freezing point \\
$L$ & $3.35 \times 10^{5}$ & $\mathrm{~J} \mathrm{~kg}^{-1}$ & latent heat of fusion for ice \\
$c_{\mathrm{i}}$ & $2.009 \times 10^{3}$ & $\mathrm{~J} \mathrm{~kg}^{-1} \mathrm{~K}^{-1}$ & specific heat capacity for ice \\
$c$ & $3.974 \times 10^{3}$ & $\mathrm{~J} \mathrm{~kg}^{-1} \mathrm{~K}^{-1}$ & specific heat capacity for seawater \\
$\beta_{S}$ & $7.86 \times 10^{-4}$ & - & haline contraction coefficient \\
$\beta_{T}$ & $3.87 \times 10^{-5}$ & - & thermal expansion coefficient \\
$g$ & 9.81 & $\mathrm{~m} \mathrm{~s}^{-2}$ & gravity constant \\
$\Gamma_{\mathrm{T}}$ & $2.2 \times 10^{-2}$ & - & thermal turbulent transfer coefficient \\
$\Gamma_{\mathrm{S}}$ & $6.2 \times 10^{-4}$ & - & salt turbulent transfer coefficient \\
\hline
\end{tabular}

conduction fluxes at the ice-water interface (i.e., between boundary layer and plume). The entrainment rate is calculated as $\dot{e}=E_{0} U \sin (\alpha)$, proportional to plume velocity and glacier slope, with coefficient $E_{0}$. The melt rate is calculated by solving heat and salt conservation at the ice-water boundary $\left(\dot{m}, T_{\mathrm{b}}\right.$ and $S_{\mathrm{b}}$ are unknown):

$\dot{m} L+\dot{m} c_{\mathrm{i}}\left(T_{\mathrm{b}}-T_{\mathrm{i}}\right)=c C_{\mathrm{d}}^{\frac{1}{2}} U \Gamma_{T}\left(T-T_{\mathrm{b}}\right)$,

$\dot{m}\left(S_{\mathrm{b}}-S_{\mathrm{i}}\right)=C_{\mathrm{d}}^{\frac{1}{2}} U \Gamma_{S}\left(S-S_{\mathrm{b}}\right)$,

where the subscript $\mathrm{i}$ for temperature and salinity refers to the inner ice, and $c$ is the specific heat capacity. The system is closed by an expression of the freezing temperature $T_{\mathrm{b}}$, which can be linearly approximated as a function of depth $Z$ $(Z<0)$ and salinity of the boundary layer $S_{\mathrm{b}}$ :

$T_{\mathrm{b}}=\lambda_{1} S_{\mathrm{b}}+\lambda_{2}+\lambda_{3} Z$,

with coefficients $\lambda_{\mathrm{i}}$ listed in Table 1. For a straight wall, $Z=$ $Z_{0}+x \cdot \sin (\alpha)$, where $Z_{0}$ is the negative depth at the grounding line $(x=0)$. Solving for Eqs. (5-7) yields a second-order polynomial equation for the melt rate $\dot{m}$, as a function of plume state variables. Note that Jenkins (2011) also uses an approximation of the melt rate equations, which resolves in $\dot{m}=M_{0} U\left(T-T_{\mathrm{f}}\right)$, where $T-T_{\mathrm{f}}$ is the plume temperature above the plume freezing point, and $M_{0}$ is a slowly varying function of ice temperature below plume freezing point. After Jenkins (2011), with a simplified formulation for the heat balance at the ice-ocean interface, $M_{0}$ varies from $6 \times 10^{-6}$ to $7 \times 10^{-6}\left({ }^{\circ} \mathrm{C}\right)^{-1}$ over a $T_{\mathrm{i}}$ range from -20 to $-2{ }^{\circ} \mathrm{C}$ and a plume freezing temperature calculated with Eq. (7) for the plume salinity varying from 0 to $35 \mathrm{psu}$ (fast entrainment of ambient salinity), resulting roughly in 0 to $-2{ }^{\circ} \mathrm{C}$. Numerically, by calculating $M_{0}$ with $M_{0}=\dot{m} \cdot\left(U\left(T-T_{\mathrm{f}}\right)\right)^{-1}$ from our experiments (fixed $T_{\mathrm{i}}=-10^{\circ} \mathrm{C}$ ), $M_{0}$ is slightly higher and can vary from $7 \times 10^{-6}$ to $12 \times 10^{-6}\left({ }^{\circ} \mathrm{C}\right)^{-1}$ (Fig. A1).

We do not use this approximation in our calculation, but this is nevertheless helpful to interpret some of the results presented in our paper, in particular in quantifying the amount of melt rate and simplifying the melt rate dependence on temperature and subglacial discharge (Appendix A).

\subsubsection{Cone plume}

The second plume model investigated in this paper is the CP model (Cowton et al., 2015). It differs from the LP model by the geometry of the plume, which resembles half of an upside-down cone (Fig. 1b). In that case, the plume has definite dimensions and fluxes are expressed in full units $\left(\mathrm{m}^{3} \mathrm{~s}^{-1}\right)$. A cross section of the plume is half a disk with area $\frac{\pi}{2} D^{2}$, where the length scale $D$ is here the cone radius at a given $x$. Equations (1)-(4) now reform for the CP model by considering melting on the diameter $2 D$ and entrainment around the $\operatorname{arc} \pi D$ :

$Q^{\prime}=(\pi D) \dot{e}+(2 D) \dot{m}$, 


$$
\begin{aligned}
& (Q U)^{\prime}=\left(\frac{\pi}{2} D^{2}\right) \frac{\Delta \rho}{\rho_{0}} g \sin (\alpha)-(2 D) C_{\mathrm{d}} U^{2}, \\
& (Q T)^{\prime}=(\pi D) \dot{e} T_{\mathrm{a}}+(2 D) \dot{m} T_{\mathrm{b}} \\
& \quad-(2 D) C_{\mathrm{d}}^{\frac{1}{2}} U \Gamma_{T}\left(T-T_{\mathrm{b}}\right) \\
& (Q S)^{\prime}=(\pi D) \dot{e} S_{\mathrm{a}}+(2 D) \dot{m} S_{\mathrm{b}} \\
& -(2 D) C_{\mathrm{d}}^{\frac{1}{2}} U \Gamma_{S}\left(S-S_{\mathrm{b}}\right)
\end{aligned}
$$

where variables, parameters and equations have the same meaning as for the LP model, and the volume flux $Q=$ $\frac{\pi D^{2}}{2} U$ is expressed in cubic meters per second.

\subsection{Numerics}

For the differential equation system of Eqs. (1)-(4) and (8)(11) we choose a classical Runge-Kutta scheme with constant step size $\Delta x$. Note that $T_{\mathrm{a}}, S_{\mathrm{a}}$ and $\sin (\alpha)$ can vary as a function of $X$, so that the model can be applied on any glacier geometry. Initial conditions for $D, U, T$ and $S$ are needed at $X=0$. Then, at every step, we first solve the boundary layer Eqs. (5)-(7) and then compute the increments in the differential equation system of the LP (Eqs. 1-4) or CP (Eqs. 8-11) model. The procedure is continued until the plume reaches zero velocity or the water surface. The code is written in Python and Fortran for future coupling.

\subsection{Initial conditions and balance velocity}

In the rest of the paper, for simplicity, we refer to the boundary condition at $x=0$ as "initial conditions" although the model equations are not time dependent. Since subglacial discharge consists of meltwater, the salinity and temperature of subglacial discharge water can be set to zero $\left(S_{0}=0\right.$ and $T_{0}=0$ ). We choose $T_{0}=0$ since the temperature of subglacial water is unknown, but for obvious reasons it cannot deviate significantly from $0{ }^{\circ} \mathrm{C}$. For conditions typical for the Greenlandic environment, we did not find any significant change in melt rate when using the pressure melting point instead of $T_{0}=0{ }^{\circ} \mathrm{C}$, since the plume temperature rapidly converges to a balance temperature close to ambient water temperature (Appendix, Fig. A3).

For both LP and CP models, initial dimensions (radius or thickness) $D_{0}$ and velocity $U_{0}$ are not known, but they are tied by subglacial discharge. In the CP case $Q_{\mathrm{sg}}=\frac{\pi}{2} D_{0}^{2} U_{0}$ (Fig. 1b), while for the LP case the subglacial discharge per glacier width $W$ enters the model equations: $q_{\mathrm{sg}}=\frac{Q_{\mathrm{sg}}}{W}=$ $U_{0} D_{0}$ (Fig. 1a).

It turns out that for a given subglacial discharge, simulated velocity rapidly adjusts to a "balance" velocity, regardless of the initial velocity (Fig. 2a), as already noticed by Dallaston et al. (2015). Analytically, the balance velocity (noted $U_{\star}(x)$ below) is solution of the plume Eqs. (1)-(2) and (8)-(9) when the transient term $U^{\prime}$ is neglected. The fast adjustment around $x=0$ (where plume dimension is small) can be explained by some rearranging into a form analogous to a first-order lin-
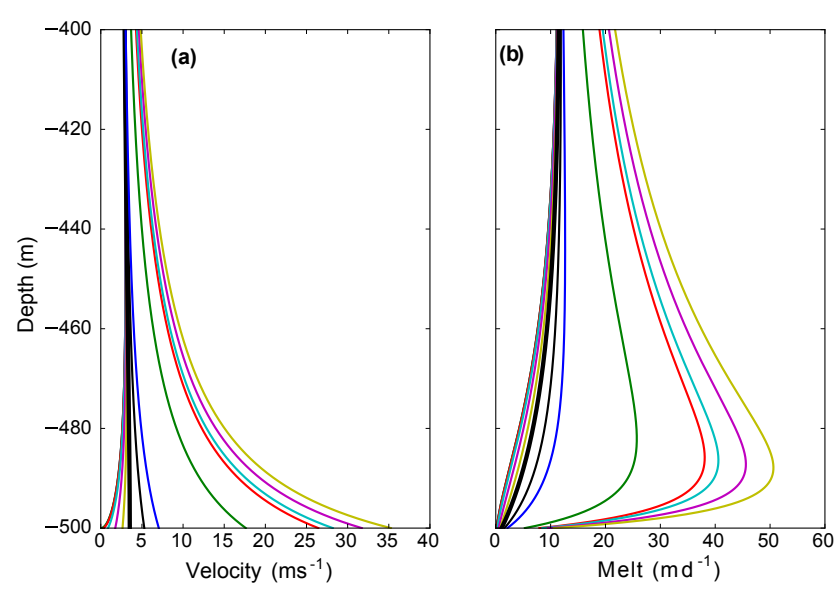

Figure 2. Different runs of the CP model for different initial velocities. Panel (a) depicts the velocity profile in the first $100 \mathrm{~m}$. All initial velocities converge within $100 \mathrm{~m}$ to the trajectory of the balance velocity $U_{\star 0}=3.5 \mathrm{~m} \mathrm{~s}^{-1}$ (thick black line). The corresponding initial radii differ thus from $300 \mathrm{~m}$ (for $U_{0}=3.5 \times 10^{-3} \mathrm{~m} \mathrm{~s}^{-1}$ ) to $3 \mathrm{~m}$ (for $U_{0}=35 \mathrm{~m} \mathrm{~s}^{-1}$ ). Panel (b) shows the corresponding melt profile. Higher initial velocities give a maximal melt rates at deeper levels. All melt rate profiles converge to the same melt rate after a certain depth.

ear differential equation for $U^{2}$ (see Appendix A2.2). The balance velocity is not necessarily constant, but a simple expression for $U_{\star 0}$ (at $\left.x=0\right)$ can be derived if the plume dimension is expressed as a function of subglacial discharge, and the melt rate is neglected compared to entrainment in the volume flux Eqs. (1) and (8) (see Appendix A1). We obtain for the LP

$U_{\star 0}=\left(\frac{\left.g \frac{\Delta \rho}{\rho_{0}}\right|_{x_{0}} \sin (\alpha)}{E_{0} \sin (\alpha)+C_{\mathrm{d}}} q_{\mathrm{sg}}\right)^{\frac{1}{3}} ，$

and for the $\mathrm{CP}$

$U_{\star 0}=\left(\frac{\pi}{2} \frac{\left(\left.g \frac{\Delta \rho}{\rho_{0}}\right|_{x_{0}} \sin (\alpha)\right)^{2}}{\left(\pi E_{0} \sin (\alpha)+2 C_{\mathrm{d}}\right)^{2}} Q_{\mathrm{sg}}\right)^{\frac{1}{5}}$.

Note that Eq. (12) is identical to the velocity derived by Jenkins (2011), and Eq. (13) is analogous to Eq. (5) in Slater et al. (2016), with the addition of the basal drag term. These balance solutions are only valid in the vicinity of the grounding line and velocity might then differ substantially as the plume develops, especially for small subglacial discharge (e.g., Magorrian and Wells, 2016). A more detailed discussion and a full, depth-dependent solution for the LP model are given in the Appendix.

Our sensitivity tests show that initial velocities higher than $U_{\star 0}$ lead to maximum melting close above the grounding line of the glacier ("undercutting") while for lower velocities the melt rate increases with height and maximum melting is located further up the calving front (Fig. 2b). We checked 


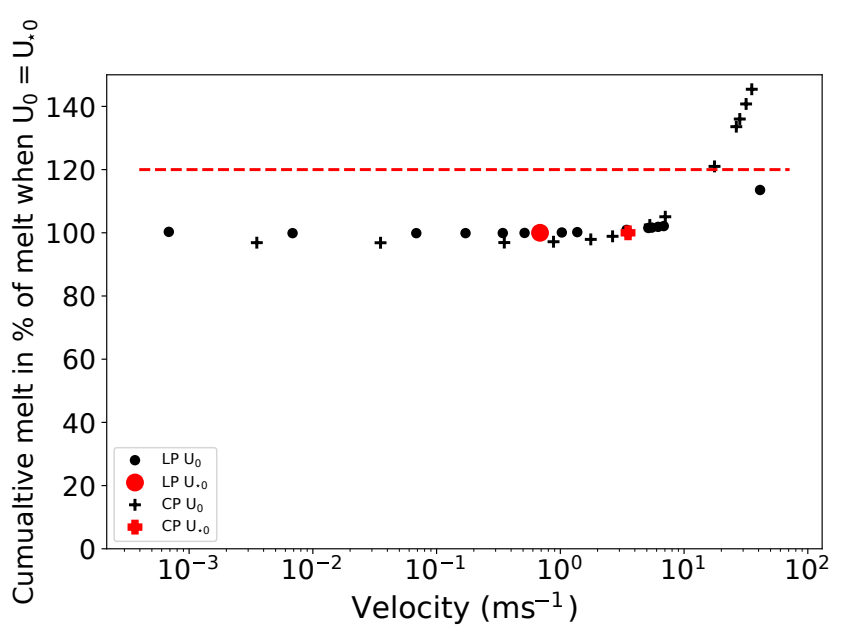

Figure 3. Sensitivity of cumulative melt rate to different initial velocities for both plume models. Melt rate (black) is in percent of the cumulative melt achieved with initial balance velocity $U_{\star 0}$ (red). Red dashed line shows $120 \%$ mark. Only very high initial velocities can appreciably increase the cumulative melt rate for the CP.

that initial velocities smaller than the balance velocity yield very small difference in the cumulative melt rate (Fig. 3), although some differences occur for larger velocities. For the LP model an initial velocity 10 times larger than the balance velocity gives a $10 \%$ higher melt rate while the $\mathrm{CP}$ model produces $25 \%$ more melting (Fig. 3). Since the velocities of subglacial discharge are mostly unknown, these results prompted us to use the balance velocity of Eqs. (12) and (13) as initial condition in all experiments described below, unless stated otherwise.

\subsection{Comparison between LP and CP models}

A direct comparison between LP (defined per unit width of the grounding line) and CP (point-wise) models requires an assumption about a length scale $W$ (for LP) and the number of sources (for CP) over which subglacial discharge is distributed. For the CP model we assumed that the entire subglacial discharge occurs through one channel in the center of the glacier $\left(Q_{\mathrm{sg}}=500 \mathrm{~m}^{3} \mathrm{~s}^{-1}\right)$. In the case of the LP model we assumed that the discharge is uniformly distributed over a fjord width $W=150 \mathrm{~m}$, so that $q_{\mathrm{sg}}=3.6 \mathrm{~m}^{3} \mathrm{~s}^{-1}$. This width is about the maximum size of the plume in the CP model, near the surface, for this setting.

Results in Fig. 4 show that simulated local melt rate can be higher in the CP model than in the LP model, but cumulative melt rate (i.e., the integral of the melt rate from the bottom and across entire surface area of the glacier front, of width $W$ ) is much higher for the LP model because of the larger surface area over which melting occurs (roughly a factor of 2 in our chosen setting).

We shall see later in this paper (Sect. 3.1) that the (local) melt rate in the LP model varies less than linearly with sub-

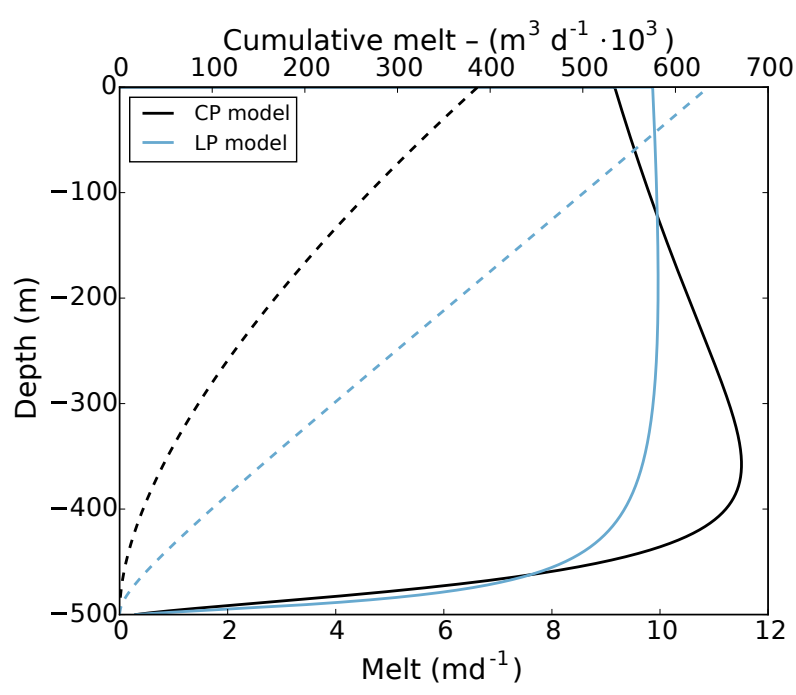

Figure 4. Melt rate profiles in a well-mixed fjord simulated by the CP model (black) and LP model (blue) for a width $W=150 \mathrm{~m}$ and the total discharge of $Q_{\mathrm{sg}}=500 \mathrm{~m}^{3} \mathrm{~s}^{-1}$. In the case of the $\mathrm{CP}$ model the total discharge is delivered through one channel in the center of the glacier; in the case of LP model the discharge is uniformly distributed with the rate $q_{\mathrm{sg}}=\frac{Q_{\mathrm{sg}}}{W}=3.6 \mathrm{~m}^{2} \mathrm{~s}^{-1}$. Both plumes start with a velocity of $U_{0}=1 \mathrm{~m} \mathrm{~s}^{-1}$. Solid lines show melt rate averaged across the plume in the case of CP model and across the full width $W$ in the case of LP model. The dashed line shows the corresponding cumulative melt rate for the entire glacier.

glacial discharge parameter $q_{\mathrm{sg}}$, and thus for a given total discharge, $Q_{\mathrm{sg}}$, cumulative LP-induced melt increases with width. As a result, for a wide glacier (i.e., the glacier which is much wider than the maximum diameter of the $\mathrm{CP}$ ), the LP model gives much higher cumulative melt rate compared to the CP model, when assuming the existence of a single subglacial channel. The situation when there is more than one channel is discussed in Sect. 4.3.

\subsection{Default experimental setting}

In the next sections we perform a number of sensitivity studies with respect to key parameters. To that end we choose a default experimental setting as a benchmark. Unless otherwise stated, we consider a $500 \mathrm{~m}$ deep, well-mixed fjord with ambient temperature $T_{\mathrm{a}}=4^{\circ} \mathrm{C}$ and salinity $S_{\mathrm{a}}=34.65 \mathrm{psu}$ (maximal melting conditions for Greenlandic fjord), with total subglacial water discharge of $q_{\mathrm{sg}}=0.1 \mathrm{~m}^{2} \mathrm{~s}^{-1}$ for the LP model or $Q_{\mathrm{sg}}=500 \mathrm{~m}^{3} \mathrm{~s}^{-1}$ for the CP model (which corresponds approximately to the discharge in August 2010 of the $5 \mathrm{~km}$ wide Store Glacier; Xu et al., 2012). Since we apply our model to glaciers in Greenland fjords, most of which do not have a floating tongue (tidewater glaciers), we therefore generally perform experiments for a vertical wall $(\sin (\alpha)=1)$. Default model parameters, including entrainment rate $E_{0}$, are indicated in Table 1. 


\section{Sensitivity experiments}

\subsection{Subglacial discharge}

It is known that melt rate depends strongly on subglacial discharge. In agreement with previous studies (Jenkins, 2011; Slater et al., 2016) our model shows a cubic root dependence of the cumulative melt rate on discharge for the LP and for the $\mathrm{CP}$ (for the high discharge range) in a well-mixed environment. However, for small discharges $\left(q_{\mathrm{sg}} \rightarrow 0\right)$ the cumulative melt rate converges to a small but not insignificant value that does not obey the power law (Fig. 5). This value represents background melt rate, or "melt-driven convection", which does not depend on discharge and can be representative for winter melt rate when subglacial discharge is very small (Magorrian and Wells, 2016).

To explain this change of power law we undertook a dimensional analysis to obtain theoretical solutions for the LP in a well-mixed fjord (Appendix A). The velocity, which determines the melt rate (Eq. A1, Fig. A1), is initially controlled by subglacial discharge (see Sect. 2.3) and subsequently accelerates as the plume develops. Our analysis shows that the plume acceleration depends on ambient hydrographic conditions, entrainment and glacier front characteristics but is independent from subglacial discharge (Eq. A17-A19). As a consequence, for a given glacier, there is a high-end regime of purely discharge-driven convection (high discharge, high melt, near-constant velocity) and a lowend regime of purely melt-driven convection (zero discharge, low melt, pure acceleration) (Eqs. A21 and A22). We defined a critical discharge $q_{\mathrm{c}}$ to characterize the transition between the two limiting regimes (Eq. A23). This critical discharge $q_{\mathrm{c}}$ depends on glacier characteristics and especially on the presence and length of a floating tongue. For tidewater glaciers, it is very low (of the order of $10^{-3} \mathrm{~m}^{3} \mathrm{~s}^{-1}$ ), so that summer discharge is sufficient to trigger a purely discharge-driven plume. In a glacier with a long floating tongue, $q_{\mathrm{c}}$ can be 2 orders of magnitude larger, and thus melt-driven convection may contribute all year long. Our approximate analytical solution for the cumulative melt rate (Eq. A20) is displayed in Fig. 5 and is in reasonable agreement with the line plume result over the full discharge range.

Note, however, that this analysis holds when the plume reaches a dynamic equilibrium. Slater et al. (2016) found deviation from the cubic root power law even for large discharge, for shallow fjord, when the adjustment length scale is large and a significant portion of the plume is not equilibrated.

In addition, as mentioned in the introduction, stratification can change this power law. We also performed experiments with stratification as in (Xu et al., 2013) for different discharges with the CP model and LP model. By assuming a melt rate equation of $\dot{m}=a \cdot Q^{\beta}+b$ as in (Xu et al., 2013), we derived $\beta$ numerically for both models and listed them in (Table ). The $\mathrm{CP}$ model shows values close to $\mathrm{Xu}$ et al.

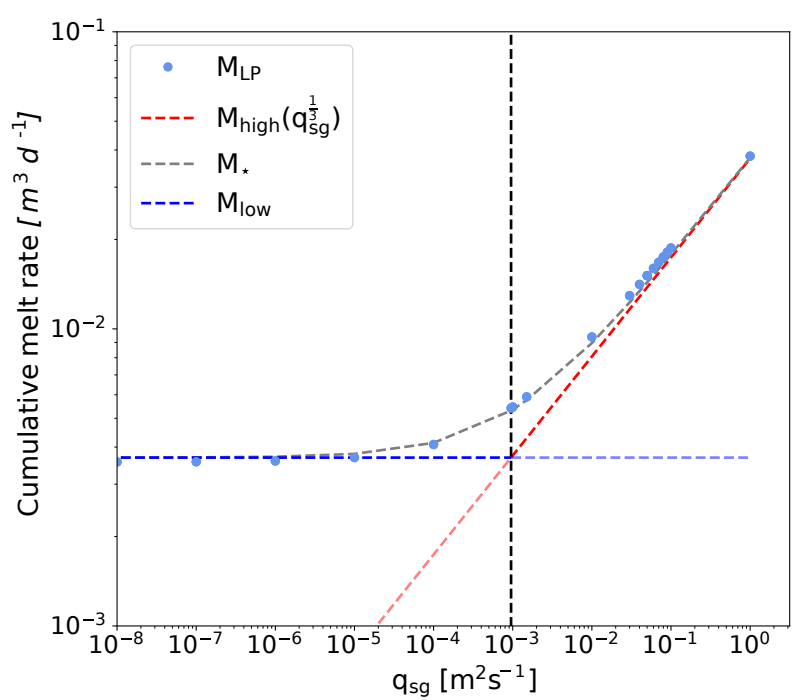

Figure 5. Cumulative melt rate of the LP model for $E_{0}=0.1$ with different discharge values for a well-mixed environment with $T_{\mathrm{a}}=4{ }^{\circ} \mathrm{C}$ and $S_{\mathrm{a}}=34.65 \mathrm{psu}$. The gray dashed line is our analytical solution for the cumulative melt rate of the LP model (Eq. A20). The red dashed and blue dashed lines indicate the limiting melt rate regimes $M_{\text {high }}$ (Eq. A21) and $M_{\text {low }}$ (Eq. A22), respectively. The transition of these regimes is defined by the critical discharge $q_{\mathrm{c}}$ (Eq. A23), depicted here with black dashed line.

(2013). Both models show an increasing exponent for lower discharge.

\subsection{Entrainment rate}

Entrainment is the mechanism through which the volume flux of the plume increases with distance from its source, as warmer, saltier fjord water mixes into the plume. This leads to more heat availability for melting, but also to decreased buoyancy - and velocity - as the plume gets saltier. Reduced velocity in turn reduces melting (Eq. 5, 6) (Carroll et al., 2016) (note the plume also becomes thicker to accommodate for increased volume flux and decreased velocity). In this section we investigate the net effect of these processes on melting for typical plume configurations.

In both plume models, entrainment depends on an entrainment rate parameter and on glacier slope, as $E_{0} \sin \alpha$ (Sect. 2.1). $E_{0}$ is not accurately known and can be regarded as a tunable parameter within a certain range of values known from previous work. Laboratory experiments for a pure vertical plume, model studies and theoretical considerations give a broad range for $E_{0}$, from 0.036 to 0.16 (Jenkins, 2011; Kaye and Linden, 2004; Mugford and Dowdeswell, 2011; Kimura et al., 2014; Carroll et al., 2015; McConnochie and Kerr, 2016). Nevertheless, glacier slope $\sin \alpha$ can vary by 2 orders of magnitude so that regardless of the value of $E_{0}$ within the reported range, tidewater glaciers $(\sin \alpha \sim 1)$ are characterized by a high-entrainment regime, while glaciers 
Table 2. Determination of the power law $\beta$ of melt rate in the equation $\dot{m}=a \cdot Q^{\beta}+b$. Separation between high $\left(Q>Q_{\mathrm{c}}\right)$ and low discharge $\left(Q<Q_{\mathrm{c}}\right)$ at a certain discharge $Q_{\mathrm{c}}$.

\begin{tabular}{lrrl}
\hline$\beta$ & $\beta$ & $Q_{\mathrm{c}}$ [discharge range] & Experiment \\
$\left(Q>Q_{\mathrm{c}}\right)$ & $\left(Q<Q_{\mathrm{c}}\right)$ & & \\
\hline 0.54 & 0.80 & $4.34[1-45] \mathrm{m}^{3} \mathrm{~s}^{-1}$ & Xu et al. (2013) \\
0.45 & 0.70 & $5.76[1-45] \mathrm{m}^{3} \mathrm{~s}^{-1}$ & CP model \\
0.33 & 0.54 & $5 \times 10^{-5}\left[10^{-5}-1\right] \mathrm{m}^{2} \mathrm{~s}^{-1}$ & LP model \\
\hline
\end{tabular}

with long floating tongue $(\sin \alpha \ll 1)$ have a low-entrainment regime.

Rearranging the LP equations (Eqs. 1 and 2) shows that entrainment acts as an effective drag $C_{\mathrm{d}}+E_{0} \sin \alpha$ (e.g., Eq. A15), with $C_{\mathrm{d}} \ll E_{0} \sin \alpha$ for tidewater glaciers (i.e., controlled by entrainment), whereas $C_{\mathrm{d}} \gg E_{0} \sin \alpha$ for glaciers with a long floating tongue (i.e., controlled by solid friction at the ice interface, insensitive to entrainment) (Fig. A3b). In contrast, plume temperature depends on the mixing ratio of meltwater to entrained water (Eqs. A9-A10), which is close to zero in tidewater glaciers, so that equilibrium plume temperature is nearly equal to ambient temperature in the full range of $E_{0}$ values, i.e., already at its maximum potential for melt and insensitive to $E_{0}$ (Fig. A3c). In the low-entrainment regime characterizing long floating tongue, the mixing ratio of melt to entrainment is significant, so that temperature is strongly controlled by $E_{0}$ (Fig. A3c).

As a result, for the LP model, an increase in $E_{0}$ leads to less melting in tidewater glaciers (Fig. 6a), where the plume slows down, but increases the melt rate for glaciers with long floating tongues, where enhanced mixing results in more heat available for melting (Fig. 6b). This effect is particularly strong for warm ambient temperature (Fig. 7) and strong discharge (Fig. 6). LP cumulative melt rate can decrease by over $42 \%$ over the full $E_{0}$ range in a tidewater glacier (Fig. 7). In the CP model, the same physics applies and determines local melt rates, but entrainment also influences the plume radius, which grows faster with larger entrainment. As a result, for the CP model, even for tidewater glaciers, where local melt rates inside the $\mathrm{CP}(\dot{m})$ decreases with $E_{0}$, the simultaneous effect of a increasing plume area in contact with the ice (2D) still dominates the calculation of the cumulative melt rate $\left(M=2 \int \dot{m}(x) \cdot D(x) \mathrm{d} x\right)$.

Thus, this leads to the statement that cumulative CP melt rate increases with increasing entrainment factor $E_{0}$ (Fig. 6c).

\subsection{Ambient temperature and stratification}

Different fjords are characterized by different temperature and salinity profiles. Since the temperature of the ocean is projected to increase with global warming, dependence of melt rate on ocean temperature is crucial to study glacier response to global warm-
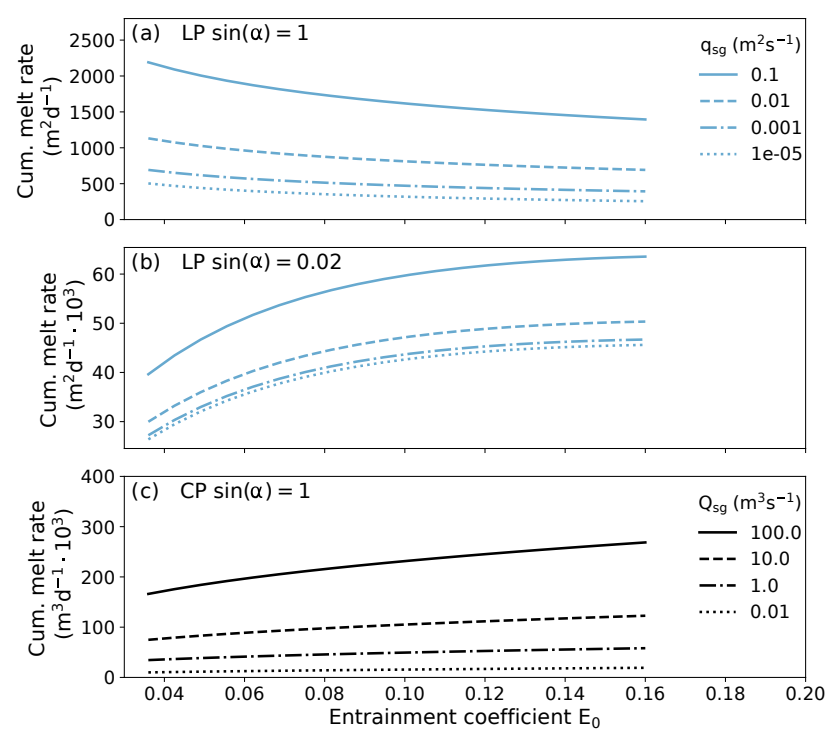

Figure 6. Cumulative melt rates of the different plume models as a function of entrainment parameter $E_{0}$ for four different discharge values. The cumulative melt rate is depicted for (a) LP of a tidewater glacier $(\sin (\alpha)=1)$, (b) LP of a long floating tongue and (c) CP of a tidewater glacier. For the LP model for $\sin (\alpha)=1$ a higher $E_{0}$ leads to lower cumulative melting opposite to the other two cases.

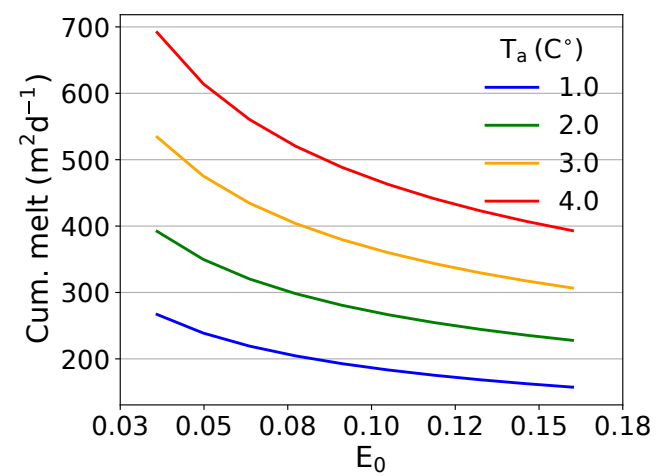

Figure 7. Cumulative melt rate in the LP as a function of entrainment parameter $E_{0}$ for $q_{\mathrm{sg}}=10^{-3} \mathrm{~m}^{2} \mathrm{~s}^{-1}$ in four different wellmixed ambient Temperatures $T_{\mathrm{a}}$, in a tidewater glacier.

ing. Previous experiments with 2-D and 3-D ocean models, as well as analytical solutions (Jenkins, 2011; Sciascia et al., 2013; Carroll et al., 2015; Jenkins, 2011; Magorrian and Wells, 2016; Slater et al., 2016; Carroll et al., 2015), demonstrated the behavior of the cumulative melt rate as a function of the ambient temperature $T_{\mathrm{a}}$. Figure 8 shows for both plume models the dependence of cumulative melt rate on temperature in a well-mixed ambient environment for different values of subglacial discharge. Both models show for small discharge a nonlinear dependence of the melt rate on water temperature. If the discharge is very small, melt-driven 
Table 3. Numerical determination of the power law $\beta$ for a melt rate dependence of $\bar{m} \propto \Delta T_{\mathrm{a}}^{\beta}$ with the thermal forcing $\Delta T_{\mathrm{a}}=T_{\mathrm{a}}-T_{\mathrm{af}}$ for tidewater glaciers. The exponent was derived for the LP and CP model for lower and higher discharge ranges. A comparison to an analytically derived value of $\beta$ for limiting discharge (low and high) ranges from literature and our study is listed for some cases additionally.

\begin{tabular}{|c|c|c|c|c|}
\hline $\begin{array}{l}\text { Discharge } \\
\left(\mathrm{m}^{2} \mathrm{~s}^{-1} \text { or } \mathrm{m}^{3} \mathrm{~s}^{-1}\right)\end{array}$ & $\begin{array}{r}\beta \\
\text { numerical }\end{array}$ & $\begin{array}{r}\beta \\
\text { analytical }\end{array}$ & Stratification & $\begin{array}{l}\text { Plume } \\
\text { type }\end{array}$ \\
\hline 0.1 & 1.2 & $1^{\mathrm{a}, \mathrm{c}}$ & well mixed & LP \\
\hline $1 \times 10^{-6}$ & 1.8 & $1.5^{\mathrm{b}, \mathrm{c}}$ & well mixed & LP \\
\hline 0.1 & 1.2 & - & realistic stratified & LP \\
\hline $1 \times 10^{-6}$ & 1.4 & 2 (linear stratified $)^{b}$ & realistic stratified & LP \\
\hline 500 & 1.2 & $1^{\mathrm{d}}$ & well mixed & $\mathrm{CP}$ \\
\hline $5 \times 10^{-3}$ & 1.5 & - & well mixed & $\mathrm{CP}$ \\
\hline 500 & 1.1 & - & realistic stratified & $\mathrm{CP}$ \\
\hline $5 \times 10^{-3}$ & 1.3 & - & realistic stratified & $\mathrm{CP}$ \\
\hline
\end{tabular}

a Jenkins (2011). ${ }^{\mathrm{b}}$ Magorrian and Wells (2016). ${ }^{\mathrm{c}}$ Sect. A2.3. ${ }^{\mathrm{d}}$ Slater et al. (2016).

convection dominates, and ambient properties determine the melting process (Slater et al., 2015). We assume a power law dependence of the cumulative melt rate per glacier area to the thermal forcing, i.e., $\bar{m} \propto \Delta T_{\mathrm{a}}^{\beta}$, where $\Delta T_{\mathrm{a}}=T_{\mathrm{a}}-T_{\mathrm{af}}$ and $T_{\mathrm{af}}$ is the freezing temperature of the sea water at the fjord bottom. As listed in Table 3 we find that the exponent $\beta$ increases with lower discharge: from 1.2 (high discharge $\left.q_{\mathrm{sg}}=0.1 \mathrm{~m}^{2} \mathrm{~s}^{-1}\right)$ to $1.8\left(q_{\mathrm{sg}}=10^{-6} \mathrm{~m}^{2} \mathrm{~s}^{-1}\right)$ for the LP and from 1.2 (high discharge $500 \mathrm{~m}^{3} \mathrm{~s}^{-1}$ ) to 1.5 (low discharge $Q_{\mathrm{sg}}=0.005 \mathrm{~m}^{3} \mathrm{~s}^{-1}$ ) for the CP. For the LP the range of this increase compares well to analytical solutions while the $\mathrm{CP}$ model can only be compared to the analytical solution of high discharge range (Table 3). The exponent also increases when using a realistic stratification (Fig. 9b). For the LP, we calculated an exponent of 1.2 for high discharge and 1.4 for low discharge, while the CP model shows a similar increase from 1.1 to 1.3. Carroll et al. (2015) showed that plume theory gives a good approximation of the outflow height for 3-D nonhydrostatic plume model but nevertheless the exponents differ slightly in the experiment by $\mathrm{Xu}$ et al. (2013).

\subsection{Glacier front angle for the line plume}

The glacier front angle $\sin (\alpha)$ linearly impacts buoyancy (Eq. 2) and entrainment. For glaciers with a floating tongue, and therefore a smaller angle $(\sin (\alpha) \ll 1)$, entrainment is reduced and so the temperature of the plume (Fig. 10b). The dependence of melt to the slope of the glacier for small discharges has been derived by Magorrian and Wells (2016). A glacier with a long floating tongue, and therefore a small angle, has a smaller average melt rate than a tidewater glacier but a higher cumulative melt rate (Fig. 6b). These high cumulative melt rates (Fig.10) occur due to the longer distance under a floating tongue over which melting occurs. Furthermore, for long floating tongues, the plume velocity accelerates along the shelf $(10 \mathrm{~b})$, with a square root dependency on

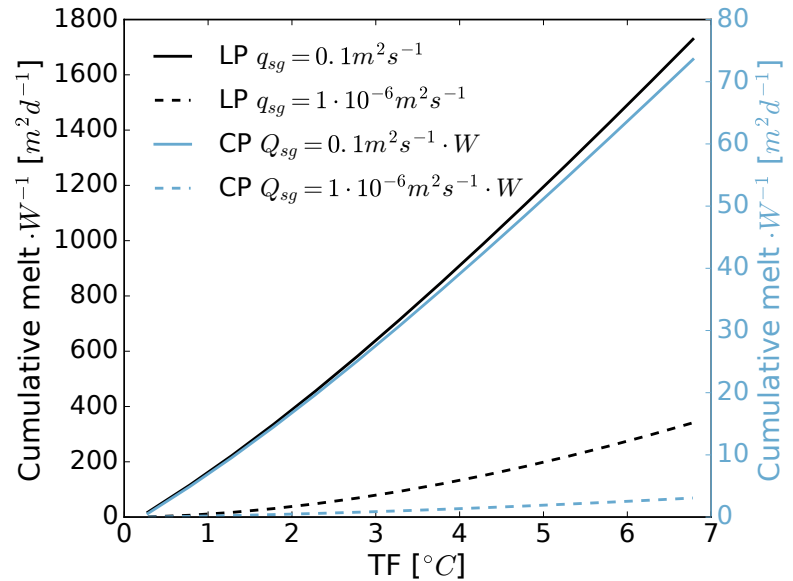

Figure 8. Cumulative melt rate per glacier width $W$ for the LP model (black) and $\mathrm{CP}$ (blue) model as a function of the thermal forcing $\left(\Delta T_{\mathrm{a}}=T_{\mathrm{a}}-T_{\mathrm{af}}\right)$ for high (solid lines) and low (dashed lines) discharge values. The experiment is for a well-mixed, $500 \mathrm{~m}$ deep and $5 \mathrm{~km}$ wide tidewater glacier $(\sin (\alpha)=1)$, with $S_{\mathrm{a}}=34 \mathrm{psu}$ and $E_{0}=0.1$.

the distance (Eq. A19). This is consistent with our analysis for a LP model in a well-mixed environment, which demonstrates that glaciers with a long floating tongue have a high critical discharge (Eq. A23) and thus a larger contribution of melt-driven convection compared to tidewater glaciers.

However, for small $\alpha$ none of the plume models are applicable along the total shelf because they do not take into account Coriolis force and plume thickness is limited by the Ekman layer depth (Jenkins, 2011). Therefore, for the total shelf area, the plume models likely strongly overestimate plume velocity and melt rate (see more in Sect. 5.1). 

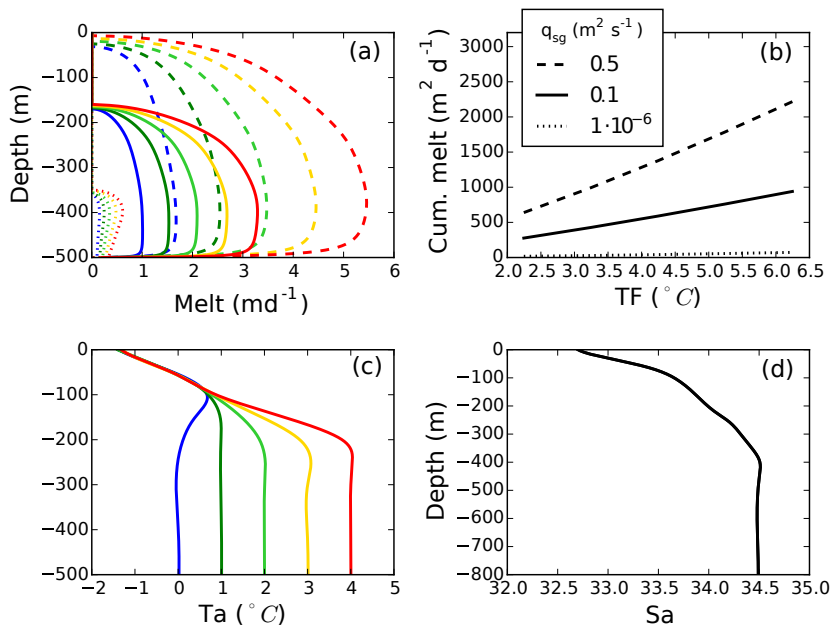

Figure 9. Influence of stratification and discharge on the melt rate profile of the LP (a). The three different discharge values $\left(q_{\mathrm{sg}}=0.5\right.$, $0.1,10^{-6} \mathrm{~m}^{2} \mathrm{~s}^{-1}$, dashed, solid, dotted) in a stratified environment for a fixed salinity profile (d) and five different temperature profiles (c) result in 15 different melt rate profiles. The melt rate of the corresponding temperature profile is displayed in the same color as well as in the same style (dashed, dotted or solid) for the corresponding discharge. Note that a very high discharge $\left(q_{\mathrm{sg}}=0.5 \mathrm{~m}^{2} \mathrm{~s}^{-1}\right)$ is needed for the plume to reach the surface. For each discharge value the corresponding cumulative melt rate is depicted (b) as a function of the thermal forcing $\left(\Delta T_{\mathrm{a}}=T_{\mathrm{a}}-T_{b}\right.$, Eq. 7) at the grounding line. For $\dot{m} \sim \Delta T_{\mathrm{a}}^{\beta}$ we found $\beta$ values of 1.2 for $\left(q_{\mathrm{sg}}=0.5 \mathrm{~m}^{2} \mathrm{~s}^{-1}\right), 1.2$ for $\left(q_{\mathrm{sg}}=0.1 \mathrm{~m}^{2} \mathrm{~s}^{-1}\right)$ and 1.4 for $\left(q_{\mathrm{sg}}=10^{-6} \mathrm{~m}^{2} \mathrm{~s}^{-1}\right)$.

\section{Comparison with general circulation models}

\subsection{Background}

Studies of turbulent plumes caused by subglacial discharge and their effect on submarine glacier melting have been performed using 2-D and 3-D nonhydrostatic general circulation ocean models (GCM) (Sciascia et al., 2013; Xu et al., 2012, 2013; Kimura et al., 2014; Slater et al., 2015). These models are much more complex than our simplified 1-D equations, which enable them to simulate plume processes in greater details. However, they require multi-dimensional grids with high spatial resolution, which is computationally prohibitive for our purpose of simulating a large number of Greenland glaciers.

These models typically parameterize unresolved, subgridscale turbulence with a turbulent diffusivity. Kimura et al. (2014) and Slater et al. (2015) tuned the diffusivity in such a way that the axisymmetric simulated plume (without ice contact) showed the same characteristics as the analytical models of Turner (1973) and Morton et al. (1956). Xu et al. (2013) used a high spatial resolution in order to reduce the amount subgrid processes. These models were run for idealized fjord configuration with constant subglacial discharge and a verti-

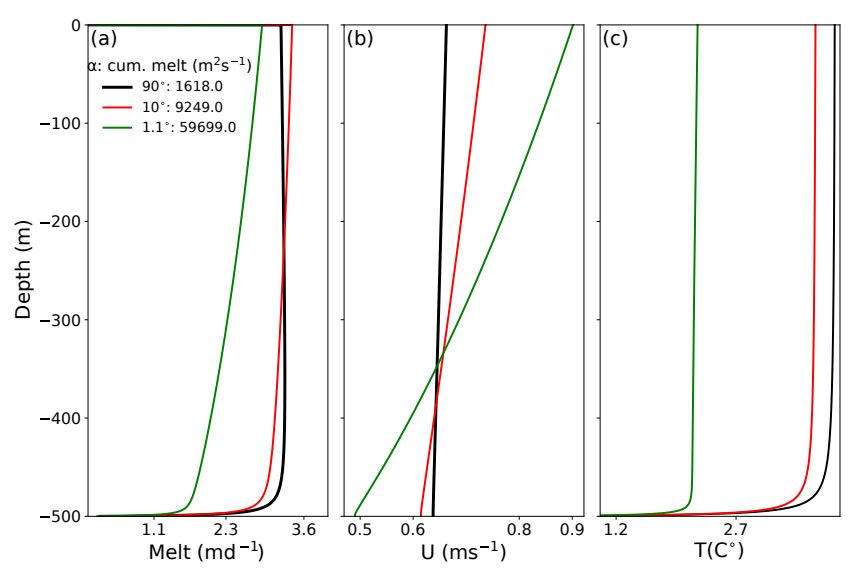

Figure 10. Melt profile (a) and corresponding plume velocity profiles (b) plume temperature (c) and salinity (d) for the LP model for different glacier types: a tidewater glacier $\left(\alpha=90^{\circ}\right)$, shelf glacier $\alpha=10^{\circ}$ and a shelf glacier with a long floating tongue $\left(\alpha=1.1^{\circ}\right)$ of $25 \mathrm{~km}$. The fjord is well mixed with $T_{\mathrm{a}}=4^{\circ} \mathrm{C}$ and $S_{\mathrm{a}}=34.2 \mathrm{psu}$, and the discharge was set to $q_{\mathrm{sg}}=0.1 \mathrm{~m}^{2} \mathrm{~s}^{-1}$ with $E_{0}=0.1$. Note that the profiles of $\alpha=90^{\circ}$ and $\alpha=10^{\circ}$ are very similar but the cumulative melt rate of the shelf glacier increased on $500 \%$. For the long floating tongue the cumulative melt rate is an order of magnitude higher.

cal ice front. In most LP experiments, where subglacial discharge was uniformly distributed along the glacier grounding line, 2-D settings were chosen. The melt rate in these experiments was computed using Eqs. (5)-(7). Since these models are more advanced compared to the simple plume model used in this study, it is informative to compare results of our plume models with these models.

\subsection{Line plume simulations}

We compare the melt rate profiles obtained in the experiments by Sciascia et al. (2013) with the LP model. Sciascia et al. (2013) used a 2-D GCM with a single $10 \mathrm{~m}$ wide grid cell for the width and a $600 \mathrm{~m}$ deep and $160 \mathrm{~km}$ long fjord with a resolution of $10 \mathrm{~m} \times 10 \mathrm{~m}$. For our simulation we used the same temperature and salinity profiles as in Sciascia et al. (2013) and the same subglacial discharge per unit of glacier front $\left(q_{\mathrm{sg}}=0.43 \mathrm{~m}^{2} \mathrm{~s}^{-1}\right)$. We used an entrainment factor of $E_{0}=0.08$ consistent with their experiments. The vertical melt rate profile of the simulated LP model resembled that of the melt rate simulated by the 2-D GCM model but is systematically overestimated by the LP model. If we apply a scaling factor of 0.48 to the results of the LP model, the two profiles are in reasonable agreement. Still, there are some differences. The melt rate simulated by Sciascia et al. (2013) declines with height while the LP model simulates a constant melt rate over a broad depth interval. This is due to the fact that the plume model is not applicable in the vicinity of the fjord surface. A similar effect is seen in the 2-D experiment of Xu et al. (2012) in Fig. 11a. Again, the LP model 
overestimates the melt rate, but when scaled up by a factor of 0.75 it yields reasonable agreement with the GCM results of Xu et al. (2012).

\subsection{Cone plume simulations}

For the channelized subglacial discharge the most recent numerical experiments by Slater et al. (2015) and Xu et al. (2013) were compared with simulations of the CP model. We used the same experimental settings (discharge, salinity and temperature profiles) as in the experiments of the 3-D models, with an entrainment rate $E_{0}=0.1$. Xu et al. (2013) used results of a survey of Store Glacier $(500 \mathrm{~m}$ deep and $5 \mathrm{~km}$ wide) performed in 2010, in particular the observed temperature and salinity profile. They performed simulations of plumes for different discharge values but the same diffusivity for a $150 \mathrm{~m}$ wide, $500 \mathrm{~m}$ deep fjord with a $1 \mathrm{~m}$ resolution near the glacier. Their sensitivity study showed that uncertainty in channel width yielded $15 \%$ uncertainty in the cumulative melt rate. Figure $11 \mathrm{~b}$ shows the dependence of the cumulative melt rate on the discharge for a single plume from Xu et al. (2013) and the CP model. Both models reveal a similar dependence of melt rate on discharge, but the $\mathrm{CP}$ model underestimates the melt rate compared to the 3D GCM. To bring the two melt rates in better agreement a scaling factor of 3.4 was needed for the CP model. Slater et al. (2015) used a coarser-resolution GCM with parameterized turbulence. They calibrated the GCM (vertical plume, without ice) against pure plume theory for each applied discharge value by adjusting the diffusivity until plume properties (temperature, salinity, thickness and velocity) matched plume theory by Turner with $E_{0}=0.1$ (Donald Slater, personal communication, 2016). Turner's plume theory is similar to our CP model (Eqs. 8-11) but omits the terms with melt rate $\dot{m}$ and drag $C_{\mathrm{d}}$. After tuning, the GCM was applied to simulate the melt rate for the same discharge values and diffusivity for a vertical ice front. Furthermore a minimum velocity of $U_{0}=0.04 \mathrm{~m} \mathrm{~s}^{-1}$ was introduced to create a background melting the is calculated with Eqs. (5)-(7). In order to simulate the same cumulative melt rate as Slater et al. (2015), distributed by 1-10 channels, a scaling factor is needed of 2.46 without calculating background melting and 1.7 with calculating background melting is needed. In contrast, the result of the GCM for the same total subglacial discharge but uniformly distributed along the whole grounding line is rather close to the results of the LP model. Indeed, for this case Slater et al. (2015) received the cumulative melt rate of $3.69 \mathrm{~m} \mathrm{day}^{-1}$, while for the LP model we receive $2.42 \mathrm{~m} \mathrm{day}^{-1}$ for $E_{0}=0.1$ and $3.71 \mathrm{~m} \mathrm{day}^{-1}$ for $E_{0}=0.036$.

\subsection{Outcome of comparison}

From this comparison of simple models with physically based model it appears that the LP model needs to be scaled down (except for Slater et al., 2015) and the CP model scaled
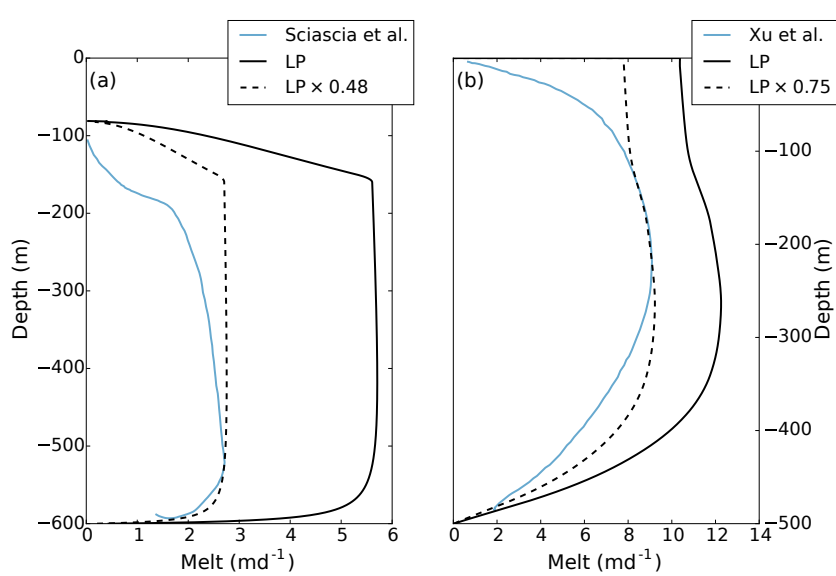

Figure 11. Comparison between LP, CP and GCM simulations. (a) Experimental results from $\mathrm{Xu}$ et al. (2012) (blue line) and LP model (black, solid line) for $Q_{\mathrm{sg}}=\frac{150}{5}=30 \mathrm{~m}^{2} \mathrm{~s}^{-1}$ and $E 0=$ $0.07, U_{0}=3 \mathrm{~m} \mathrm{~s}^{-1}$ and the same stratification as in Xu et al. (2012). A scaling factor of 0.74 is needed to match the two melt profiles (black, dashed line). (b) Average melt rate over a $150 \mathrm{~m}$ wide and $500 \mathrm{~m}$ deep glacier part as a function of discharge localized in one channel. Following $\mathrm{Xu}$ et al. (2013), for the $x$ axis, the discharge $Q_{\text {sg }}$ was divided by the area of the ice face $A_{\text {ice }}=150 \times 500 \mathrm{~m}^{2}$ so that $q_{\mathrm{sg}}=50 \mathrm{~m} \mathrm{day}^{-1}$ corresponds to $Q_{\mathrm{sg}}=43.4 \mathrm{~m}^{3} \mathrm{~s}^{-1}$. The numerical results of Xu et al. (2013) are displayed with the blue line. Taking the same conditions $\left(T_{\mathrm{a}} S_{\mathrm{a}}, Q_{\mathrm{sg}}\right)$ and an entrainment factor of $E_{0}=0.1$ the $\mathrm{CP}$ model gives the solid black line. To match the experiment a scaling factor of 3.40 is needed (black, dashed line).

up. The scaling factor is of the order of 1. Most importantly, CP and LP models reveal a similar qualitative behavior to much more complex and computationally demanding GCMs as shown in Xu et al. (2012), Slater et al. (2015) and Sciascia et al. (2013).

\section{Comparison with empirical data}

Few studies exist in which submarine melt has been calculated directly based on field measurements. We used here the available data to test the LP and CP models against observations. However, the results have to be observed with caution since a single temperature profile does not necessarily represent monthly or even annual temperature profile. As Jackson et al. (2014) shows, for Sermilik Fjord and Kangerdlugssuaq Fjord in the winter months the properties, including heat content, can undergo great variability within timescales of 3 to 10 days (Jackson et al., 2014). Furthermore, uncertainties in the estimation of melt rates from fjord flux gates have been analyzed in depth by Jackson and Straneo (2016) by considering the total heat and salt budget of the fjord. Thus, when considering the derived melt fluxes from field measurements we have to keep in mind the other possible melt rate flux contributors as sea ice or melting ice bergs. 


\subsection{Petermann Glacier}

For the years 2002-2006 Rignot and Steffen (2008) calculated the melt rate of the floating tongue of Petermann Glacier obtained from ice flux divergence. They detected four large channels incised into the underside of the floating tongue. Due to its long floating tongue, the estimated melt rate is reliable because it is less affected by errors in estimating the calving rate as it is the case for tidewater glaciers. For modeling the melt rate of Petermann Glacier we used temperature and salinity profile in the fjord in front of the floating tongue measured in the year 2003 by Johnson et al. (2011). We also use the data from Morlighem et al. (2014) to define the margins of the Petermann Glacier and to compute the average one-dimensional profile of the floating tongue. We then use a polynomial fit to smooth the profile of the floating tongue. Figure 12a shows the annual mean melt rate calculated with the LP model for $E_{0}=0.16$ and $E_{0}=0.036$. Our calculated melt rates were compared to the width-averaged melt rate derived by Rignot and Steffen (2008), which is mostly dominated by the four channels that have maximal melt rates of $30 \mathrm{~m} \mathrm{day}^{-1}$. Even for a minimum discharge of $10^{-5} \mathrm{~m}^{2} \mathrm{~s}^{-1}$ (as discussed in Sect. 3.1) and with $E_{0}=0.036$, the LP model significantly overestimates the melt rate beyond a very narrow range (few kilometers) directly next to the grounding line. This is an expected result because for long floating tongues at a certain length $L$, Coriolis force becomes important for small to moderate Rossby numbers $R$ and a (horizontal) plume velocity $U$ if $\frac{U}{f L}<1$. On this length scale the plume flow gets deflected (to the right here) and will be dominated by geostrophic flow as modeled by Gladish et al. (2012). Yet this is not taken into account in our simple plume model, as discussed in Sect. 3.4. However, when using the $\mathrm{CP}$ model and a large discharge given by the total runoff over the catchment area distributed over four identical subglacial channels, we receive very low melt rates (Fig. 12b). It is clear that the LP model is in better agreement than the CP model at simulating the melt rate near the grounding line of the Petermann glaciers but a correction for the Coriolis effect is required further from the grounding line.

\subsection{West Greenland glaciers}

In a small fjord in West Greenland the melt rate of four glaciers was determined by measuring the fjord salinity, temperature and velocity close to the glacier fronts (Rignot et al., 2010). In Torsukattak fjord (TOR) the average and cumulative melt represents the melt rates of both glacier fronts together (Sermeq Avangnardleq and Sermeq Kujalleq) since the fronts are situated in the same head of the fjord branch. The two other glaciers, Kangilerngata Sermia (KANGIL) and Eqip Sermia (EQIP), enter different fjords. The measured velocity in front of EQIP does not show an upwelling pattern but more a right-to-left circulation; nevertheless we also calculated the melt rate with our plume models for EQIP.
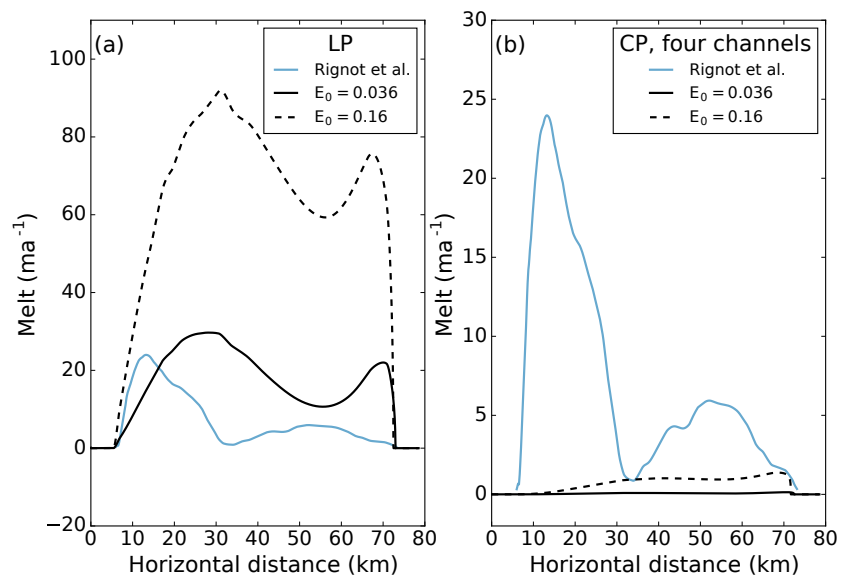

Figure 12. Melt rate of (a) LP model simulated over the long floating tongue of Petermann Glacier with a minimal discharge of $Q_{\min }=10^{-5} \mathrm{~m}^{2} \mathrm{~s}^{-1}$ for the minimal $\left(E_{0}=0.036\right)$ and maximal $\left(E_{0}=0.16\right)$ value (black lines) of the entrainment parameter. In panel (b) we used the maximum discharge $Q_{\mathrm{sg}}=296 \mathrm{~m}^{3} \mathrm{~s}^{-1}$ (total runoff assumed only in summer) distributed over four channels to compute the melt rate with the $\mathrm{CP}$ model. As forcing variables we used the fjord's temperature and salinity profile in front of the floating tongue for the year 2003 summarized by Johnson et al. (2011), and from Morlighem et al. (2014) we determined the glacier thickness and depth of the floating tongue (see Sect. 5.1 for details). For both $E_{0}$ the melt rate is highly overestimated with the LP model and underestimated with the CP model. The empirical melt rate estimated by Rignot and Steffen (2008) is displayed with the blue line. Note the different vertical scale on the panels.

For all glaciers we took the total width of the glacier to determine the subglacial discharge per unit of length for the LP model and determined the average depth of the grounding line as a starting point for the LP model. The total subglacial discharge $Q_{\mathrm{sg}}$ was taken from the table of Rignot et al. (2010) We then compare our simulations to the average melt rate determined by Rignot et al. (2010). As shown in the experiment by Slater et al. (2015), a large number of channels act like an LP but we also computed cumulative melt, assuming the existence of one large single CP starting at the maximum depth of the grounding line. Table 4 shows the ratio between observed and simulated melt rate for two types of plume models and two values of entrainment rate factor $E_{0}$. For KANGIL and EQIP results of the LP model are in reasonable agreement with measurements, especially for the smallest $E_{0}$ value (45-105\%). Although for EQIP the agreement is the best with the LP model, the lack of upwelling circulation indicates that the plume model may not be applicable to this glacier and therefore this agreement may be a pure coincidence. The melt rate ratio of one $\mathrm{CP}$ shows rather poor results $(1-5 \%)$. We also compared our model with the data from Fried et al. (2015) for Kangerlussuup Sermia Glacier, which is located in West Greenland, northward of the previously discussed glaciers. Realistic temperature stratifica- 
Table 4. Simulated cumulative melt rate $(\%)$ of empirical estimated cumulative melt rate for different entrainment rates for three West Greenland glaciers.

\begin{tabular}{lrr|lrr|lrr}
\hline & \multicolumn{2}{c|}{ TOR } & \multicolumn{2}{c|}{ KANGIL } & \multicolumn{2}{c}{ EQIP } \\
\hline Model & $E_{0}$ & Melt ratio (\%) & Model & $E_{0}$ & Melt ratio (\%) & Model & $E_{0}$ & Melt ratio (\%) \\
\hline LP & 0.036 & 57 & LP & 0.036 & 45 & LP & 0.036 & 103 \\
CP & 0.036 & 1 & CP & 0.036 & 2 & CP & 0.036 & 5 \\
LP & 0.16 & 22 & LP & 0.16 & 19 & LP & 0.16 & 44 \\
CP & 0.16 & 2 & CP & 0.16 & 3 & CP & 0.16 & 8 \\
\hline
\end{tabular}

tion can lead to maximal melting at the bottom of tidewater glaciers near the grounding line (e.g., Fig. 9a). This maximal melting at the bottom may cause so-called undercutting, which may enhance mass loss by calving (Rignot et al., 2015). Fried et al. (2015) found that $80 \%$ of the tidewater glacier is undercut by $45 \mathrm{~m}$ in average. The glacier releases subglacial discharge via two large channels, but their corresponding melting contributes only $15 \%$ of the total melt of the glacier front. Furthermore, Carroll et al. (2016) showed that the simulated melt rate of a single cone plume is about 2 orders of magnitudes lower than the spatially averaged melt rate by Fried et al. (2015). Thus we investigate whether the LP model can calculate the average melting by assuming that the $250 \mathrm{~m}$ deep glacier is undercut below 50 meters depth, with an angle of $77^{\circ}$ to achieve the observed undercutting (Fig. 13a). Bartholomaus et al. (2016) give the belonging CTD data and estimate an summer discharge. We use the CTD closest to the glacier front in summer 2013 and the mean summer discharge $\left(208 \mathrm{~m}^{3} \mathrm{~s}^{-1}\right)$ per glacier width ( $3 \mathrm{~km})$ as input data for the LP model. Fried et al. (2015) find a total melt rate of $2 \mathrm{mday}^{-1}$ for the whole calving front. They assumed that the glacier is only undercut by submarine melting, such that the distance of grounding line to the overhang position subtracted by the glacier's velocity gives the submarine melt value. With these input data and an entrainment rate factor of $E_{0}=0.036$ we achieve an average melt rate of $1.5 \mathrm{~m} \mathrm{day}^{-1}$ (Fig. 13). This value is close to the empirical data but this plume would not result in the mentioned undercutting depth, since it penetrates up to $10 \mathrm{~m}$ below the sea surface. The entrainment factor $E_{0}=0.16-0.13$ lets the plume stop at $50 \mathrm{~m}$ depth but their melting corresponds only to $50 \%$ of the empirical data for the total melt rate. If the LP model is correct, additional fjord circulation makes up $50 \%$ of the melting. Furthermore, CTD profiles close to the glacier might be diluted by near local surface runoff or calving and thus cooling and freshening of the surface ocean waters. Thus deriving the melt rate from a such a CTD profile can lead to high uncertainty ranges.

\subsection{Helheim}

Sutherland and Straneo (2012) used results of a field campaign in Sermilik fjord in summer 2009 in which tempera-
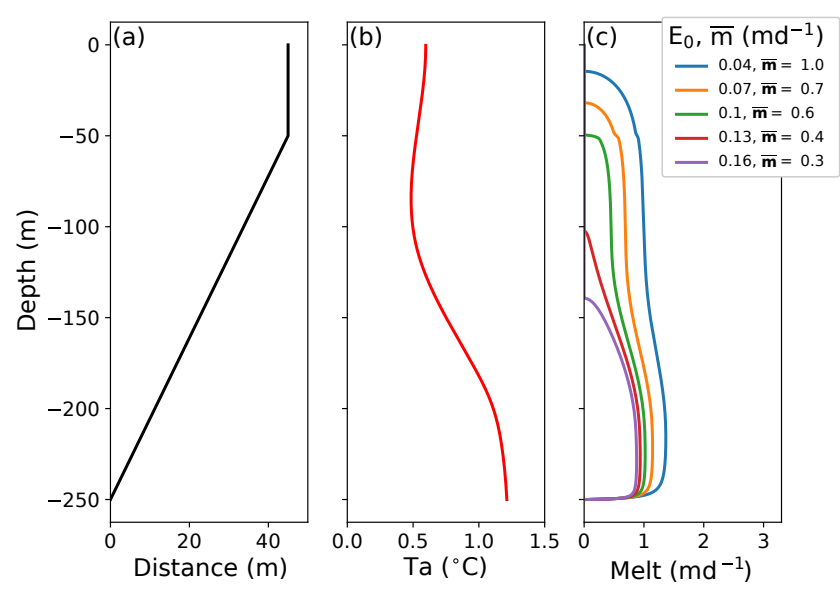

Figure 13. Kangerlussuup Sermia average undercut profile at the terminus (a) with the assumed temperature profile (b) give different melt rate profiles (c) simulated for different $E_{0}$ and same $Q_{\mathrm{sg}}=208 \mathrm{~m}^{3} \mathrm{~s}^{-1}$. All average melt rates are below the determined $2 \mathrm{~m}$ day $^{-1}$ by Fried et al. (2015).

tures, salinities and velocities were measured at seven stations in the fjord to calculate the melt rate of Helheim Glacier. We applied the temperature and salinity profile closest to the glacier for the LP model to simulate the melt rate for comparison. We assume, following Sutherland and Straneo (2012), that Helheim Glacier is a tidewater glacier and has a depth of $700 \mathrm{~m}$ and a width of $6 \mathrm{~km}$ and the subglacial discharge of $5.1 \pm 0.76 \mathrm{~km}^{3} \mathrm{a}^{-1}$ (summer 2008; Andersen et al., 2010). Figure 14 shows the simulated melt rates over for different $E_{0}$ with the average subglacial discharge. Our best fit computes an average melt rate of $1.7 \mathrm{~m} \mathrm{day}^{-1}$ (1.8 $\mathrm{m} \mathrm{day}^{-1}$; Sutherland and Straneo, 2012) with an entrainment factor $E_{0}=0.036$.

\subsection{Store Glacier}

Another well-documented glacier is Store Glacier. Xu et al. (2013) estimated an average submarine melt rate of $3.0 \pm$ $1.0 \mathrm{~m} \mathrm{day}^{-1}$ in summer (Sect. 4) while new calculations, thanks to new bathymetry data, reveal a melt rate of $4.5 \pm$ $1.5 \mathrm{~m} \mathrm{day}^{-1}$ (Chauche, 2016). Additionally, Chauche (2016) conducted a survey to determine average melt rate and sub- 

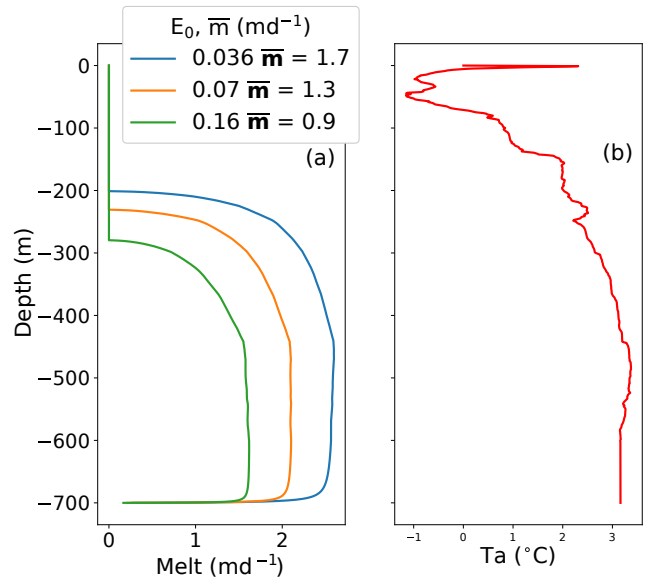

Figure 14. Three vertical melt rate profiles of the LP model (a) for three different entrainment coefficients $E_{0}$ for Helheim Glacier. With a discharge of $2.69 \times 10^{-2} \mathrm{~m}^{2} \mathrm{~s}^{-1}$ and $E_{0}=0.036$ we obtain an average melt rate of $\bar{m}=1.7 \mathrm{~m} \mathrm{a}^{-1}$ close to Sutherland and Straneo (2012) $\left(1.8 \mathrm{~m} \mathrm{day}^{-1}\right)$.

Table 5. Comparison of the melt rate calculated with the LP model and the empirical data obtained with the Gade and Motyka model (Chauche, 2016).

\begin{tabular}{lrr}
\hline & $\begin{array}{r}\text { Melt }\left(\mathrm{m} \mathrm{day}^{-1}\right) \\
(\text { Chauche, 2016) }\end{array}$ & $\begin{array}{r}\text { Melt }\left(\mathrm{m} \mathrm{day}^{-1}\right) \mathrm{LP} \\
\left(E_{0}=0.036\right)\end{array}$ \\
\hline Gade & $2.2 \pm 0.5$ & $0.6 \pm 0.1$ \\
Motyka & $1.6 \pm 0.4$ & $0.7 \pm 0.3$ \\
Average & $1.9 \pm 0.5$ & $0.7 \pm 0.2$ \\
\hline
\end{tabular}

glacial discharge from November 2012 until May 2013. Two different techniques were used, which we reference as Gade (Gade, 1979) and Motyka (Motyka et al., 2003) (see Fig. 15a). The Motyka technique is based on conservation of heat, salt and volume. The Gade technique is based on the identification and quantification of different processes (i.e., submarine melting, runoff mixing, thermal cooling, local sea ice formation) that can be identified by their typical temperature-salinity (TS) properties in a TS plot (i.e., Straneo et al., 2011). To simulate melt rates, we used the LP model with $E_{0}=0.036$ and an input subglacial discharge determined by Motyka and Gade with the corresponding temperature and salinity profiles. Results from the LP model are biased low compared to the measurements (Fig. 15b), with melt rate underestimated by $75 \%$ in average (Table 5). Note that the Motyka method comes with large error bars for both subglacial discharge and the corresponding melt rate, which accommodate for the LP model bias (Fig. 15). Stated uncertainties for the Gade method are smaller and are not consistent with the LP model results.
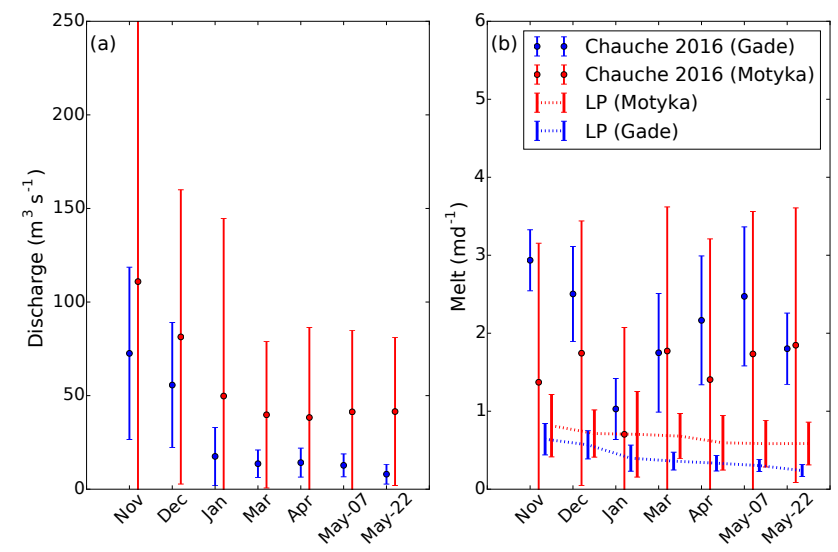

Figure 15. (a) Estimated subglacial discharge of Store Glacier for winter 2012/2013 from (Chauche, 2016). Red ranges give subglacial discharge estimates by the Motyka method and blue ranges by the Gade method and (b) the corresponding melt rate profiles. Simulated melt rates by the LP model with $E_{0}=0.036$ are depicted as the red dotted line (subglacial discharge from Motyka) and blue dotted line (subglacial discharge from Gade model).
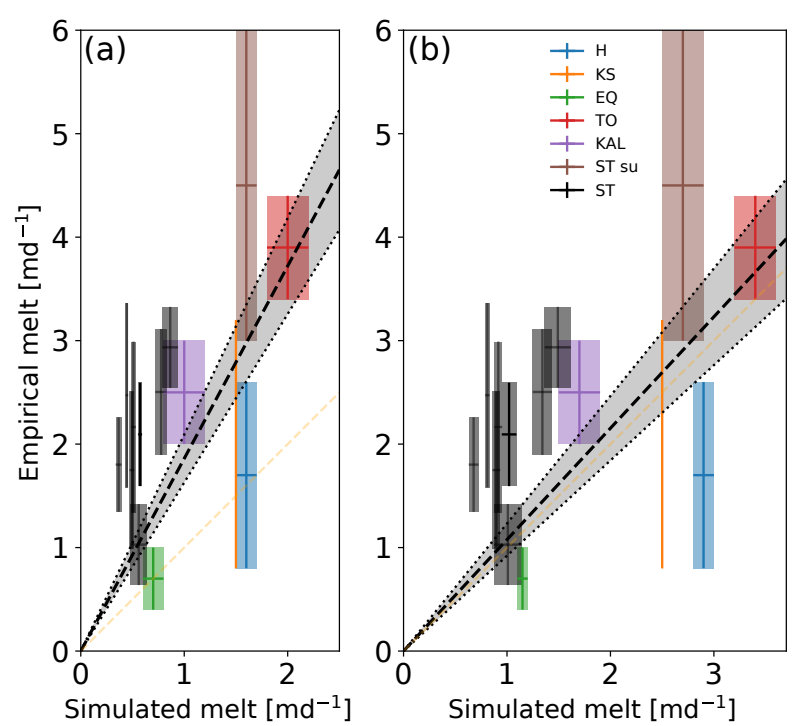

Figure 16. Measured versus simulated melt rate for a number of glaciers, for data given in Table 6 . The squares represent error bars in measured and simulated melt rate. The black regression line with 1-sigma uncertainty range indicates the average scaling coefficient of 1.85 required to match observations given model parameters. In both panels, entrainment rate is 0.036. Panel (a) shows model simulations with default values for the heat transfer coefficient $\Gamma_{\mathrm{T}}=2.2 \times 10^{-2}$, while panel (b) shows simulation with $\Gamma_{\mathrm{T}}=4.2 \times 10^{-2}$, which produces a scaling coefficient closer to one. Glacier abbreviations are shown in Table 6. Note that only one representative value for the Store Glacier in winter was used, as reported in Table 6 . 
Table 6. Estimated subglacial discharge $Q_{\mathrm{emp}}$ and melt rate $m_{\mathrm{emp}}$ for a number of glaciers and corresponding melt rate $m_{\mathrm{lp}}$ from LP model simulations. Values of Store winter are taken from the Gade model (Fig. 15). For each glacier, local hydrography (temperature and salinity profiles) and measured subglacial discharge is used to drive the LP model. Ranges indicate measurement errors. Errors in subglacial discharge are propagated to errors in simulated melt rate via the LP model. For the Store Glacier in winter we only report a representative value in the table, where both mean and error were averaged. Simulated melt rate $m_{\mathrm{LP}}$ is obtained with $E_{0}=0.036, \Gamma_{\mathrm{T}}=2.2 \times 10^{-2}$. Melt rate $m_{\mathrm{LP}}^{\star}$ with modified $\Gamma_{\mathrm{T}}=4.2 \times 10^{-2}$ is also provided.

\begin{tabular}{lrrrr}
\hline & $\begin{array}{r}\mathrm{Q}_{\mathrm{emp}} \\
\left(\mathrm{m}^{3} \mathrm{~s}^{-1}\right)\end{array}$ & $\begin{array}{r}m_{\mathrm{emp}} \\
\left(\mathrm{m} \mathrm{day}^{-1}\right)\end{array}$ & $\begin{array}{r}m_{\mathrm{LP}} \\
\left(\mathrm{m} \mathrm{day}^{-1}\right)\end{array}$ & $\begin{array}{r}m_{\mathrm{LP}}^{\star} \\
\left(\mathrm{m} \mathrm{day}^{-1}\right)\end{array}$ \\
\hline Helheim (H) & $137-189$ & $0.7-2.6$ & $1.6-1.7$ & $2.9-3.0$ \\
Kangerlussuup Sermia (KS) & 208 & $0.8-3.2$ & 1.5 & 2.5 \\
Eqip Sermia (EQ) & $101-121$ & $0.4-1.0$ & $0.7-0.8$ & $1.1-1.2$ \\
Sermeq Avangnardleq and Sermeq Kujalleq (TO) & $559-679$ & $3.4-4.4$ & $2.0-2.2$ & $3.2-3.6$ \\
Kangilerngata Sermia (KAL) & $208-328$ & $1.9-3.0$ & $1.0-1.2$ & $1.5-1.9$ \\
Store (winter, Gade model) (ST) & $8-73$ & $1.7-2.7$ & $0.5-0.7$ & $0.9-1.1$ \\
Store (summer) (ST su) & $201-291$ & $3.0-6.0$ & $1.4-1.7$ & $2.4-2.9$ \\
\hline
\end{tabular}

\subsection{Summary}

We tested both line and cone plume models against available empirical data for melt rate, and the line plume was best suited to reproduce observations (Table 4). Table 6 and Fig. 16 provide for each glacier the measured discharge and melt rate, with error bars, and corresponding range in simulated melt rate (when errors in observed discharge are taken into account as input). When default drag, heat and salt transfer coefficients are used, the simulated melt rate tends to underestimate observed melt rate, and thus the best match was obtained with an entrainment rate, $E_{0}=0.036$, on the lower end of our range (e.g., see Fig. 7 for how melt rate varies with $E_{0}$ ). Nevertheless, three glaciers (Helheim, Eqip Sermia and Kangerlussuup Sermia) out of seven match observations within the error bars. Varying other model parameters can change the mean but not the spread of simulated melt rate across glaciers and discharge ranges. For instance, if the heat exchange coefficient is increased to $\Gamma_{\mathrm{T}}=4.2 \times 10^{-2}$ (instead of the default $\Gamma_{\mathrm{T}}=2.2 \times 10^{-2}$ ), the bias can be reduced and simulated melt rates are close with observations (Helheim and Eqip Sermia fall out, conversely). Figure 16 shows a comparison of measured and simulated melt rate with the modified heat transfer coefficient. Clearly, many fjord processes are not taken into account in this simplified approach. For example, the circulation in front of Eqip Sermia was mostly horizontal (Rignot et al., 2010) instead of the vertical upwelling represented in the model. There are also issues with the measurements themselves, such as time sampling or difficulties to retrieve discharge and melt rate, as seen for the Store Glacier (Fig. 15) or for Helheim, where CTD profiles for temperature and salinity were taken 1 year after discharge rates measurements. Nevertheless, the simple line plume model is in general agreement with the observations (Fig. 16) and shows a correlation coefficient of 0.7 (Fig. 16b) with the modified heat transfer coefficient. The theoretical background and similar dependency on discharge compared to more complex models (see previous sections) make it suitable for modeling studies over a larger number of Greenland glaciers, and to investigate melt rate response to future changes in subglacial discharge and fjord temperature.

\section{Conclusions}

We presented two simple models for simulation of the submarine melt rate of marine-terminating glaciers, the so-called cone plume and line plume models, and studied sensitivity of these two models to different forcings (fjord temperature, stratification, subglacial discharge) and model parameters (entrainment parameter $E_{0}$ ). We also compared these models with results of experiments performed with 2-D and 3-D ocean GCM by Slater et al. (2015) and Xu et al. (2013). Lastly we compared the results of simulations of the LP and CP models with empirical estimates of melt rate for several Greenland glaciers.

Our analysis demonstrates that for small subglacial discharge, typical for winter conditions, cumulative melt does not depend on the discharge. For high discharge typical of summer conditions we found a power dependence of $1 / 3$ of submarine melt on subglacial discharge for the LP models, which is consistent with previous studies. We found a theoretical explanation of this behavior, explained in Appendix A. Furthermore, we found that the power dependence to the ambient temperature in a well-mixed environment is 1.7-1.8 for lower discharges and is only 1.2 for the higher discharge for both models.

We investigated the sensitivity of the melt rate to the entrainment parameter $E_{0}$ that was used to parameterize turbulent entrainment into the plume. For a tidewater glacier the cumulative melt rate of the LP model increases with decreasing $E_{0}$ while it decreases for the CP model. This is explained by the fact that although in both cases higher entrainment rate 
slows down the plume and reduces the melt rate per unit of area, for the $\mathrm{CP}$, this effect is overcompensated by the widening of plume for the higher entrainment coefficient. In general, we found a notable effect of the entrainment parameter on the melt rate for the range of entrainment parameter given in the literature. The uncertainty range of $E_{0}$ can have the same effect as $1{ }^{\circ} \mathrm{C}$ change in ocean temperature.

Our comparison of the CP and LP models to results of 3D GCM experiments showed qualitatively similar melt rate profiles.

In most cases, the LP model overestimates the results of the GCM by approximately a factor of 2 , while the CP model underestimates melt rate from GCMs. More importantly, we find the same power law dependence of melt rate on subglacial water discharge as in Slater et al. (2016), for given ambient hydrographic conditions. As a result, with a constant scaling factor of the order of 1 , the simplified models can reproduce a wide range of melt rates spanning several orders of magnitude.

In the case of the long floating tongue, like the Petermann Glacier, the LP model significantly overestimates the melt rate outside of the narrow zone along the grounding line, which is probably due to the missing Coriolis force in the plume models.
Although it is known that in summer a part of the subglacial meltwater is delivered in the fjord through several channels, we found that the submarine melt rate associated with the discharge through the channels and better described by the CP model makes up only a small amount of the empirically estimated total melt rate of a glacier front. Furthermore the total number of channels for every summer is unknown for different glaciers. When we compare the LP model to empirical data, it is evident that the LP model is more appropriate than the CP model for simulation of both winter and summer melt of real Greenland glaciers. However, the model has to be adjusted for individual glaciers since the scaling parameter is not the same for different glaciers. Thus, for the future we will use the tuned LP model coupled to a 1-D ice flow model to determine the importance of submarine melt rate to glacier dynamics.

Code availability. The code for the line and cone plume, written in Python, is available as Supplement.

Data availability. Data were either received via personal communication (see acknowledgments) or digitized with https://automeris. io/WebPlotDigitizer/ out of the figures of the cited paper. 


\section{Appendix A: Semi-analytical solutions for the LP model}

In this Appendix, we analyze the LP model equations in order to derive approximate analytical solutions. This in turn helps to interpret the results of the numerical experiments presented in this paper, performed with the more complete plume models from Jenkins (2011). First analytical solutions for the LP model were undertaken by Linden et al. (1990) and summarized in Straneo and Cenedese (2015). Slater et al. (2016) previously presented approximate analytical solutions for the LP model for higher discharge ranges. Jenkins (2011) noticed that for strong discharge, plume velocity in the LP model does not change much with depth and is thus similar to the initial balance velocity (our Eq. 12). Magorrian and Wells (2016) covered the case for small discharge. The reasoning in this Appendix provides a unifying solution for small and large discharge with the LP model applied at tidewater glacier and glacier with long floating tongues.

We restrict the analysis to the typical conditions of a $500 \mathrm{~m}$ deep Greenlandic fjord $\left(T_{\mathrm{a}} ; 0-4{ }^{\circ} \mathrm{C}\right)$.

\section{A1 Simplified melt rate equation}

After Jenkins (2011), the melt rate can be approximated as

$\dot{m} \approx M_{0} \cdot U \cdot \Delta T$,

where $\Delta T=T-T_{\mathrm{f}}$ is the temperature above freezing and $M_{0}$ is a slowly varying function of ice temperature below freezing point, which can be considered constant for the purpose of this Appendix. Freezing point temperature is given by $T_{\mathrm{f}}=\lambda_{1} S+\lambda_{2}+\lambda_{3} Z$. We run several experiments in a typical parameter range for tidewater and long floating tongue glaciers in Greenland's fjords and could confirm that the approximation is accurate for the LP model (Fig. A1a). The parameters were $T_{\mathrm{a}}\left(0-4{ }^{\circ} \mathrm{C}\right), q_{\mathrm{sg}}\left(1 \times 10^{-5}-0.1\right), E_{0}(0.036-$ $0.16)$ and $\sin \alpha(0.02-1)$ for constant depth of $500 \mathrm{~m}, T_{\mathrm{i}}=$ $-10^{\circ} \mathrm{C}$ and $S_{\mathrm{a}}=34.2$. With linear regression we found an average value for $M_{0}=8.8 \times 10^{-6}$. Let $T_{\mathrm{e}}=\frac{E_{0}}{M_{0}} \sin \alpha$, the entrainment-equivalent temperature $\left({ }^{\circ} \mathrm{C}\right)$, be a measure of the ratio of entrainment to melting (it corresponds to the temperature for which melting equates entrainment). We have

$$
\frac{\dot{m}}{\dot{e}} \approx \frac{\Delta T}{T_{\mathrm{e}}} \ll 1
$$

in all experiments (Fig. A1b), consistent with the ranges for $E_{0}(0.036-0.16)$ and $\sin \alpha(0.02-1)$, so that $T_{\mathrm{e}}$ spans 2 orders of magnitude, roughly $10^{2}-10^{4}{ }^{\circ} \mathrm{C}$.

\section{A2 Balance regime}

In Fig. 2 we showed that $\mathrm{CP}$ velocity rapidly converges regardless of initial velocity. This has been also shown by Dallaston et al. (2015) for the LP and also holds for the plume temperature, salinity and melt rate. Here we derive analytical solutions for these convergence values (indicated with $\star$ ) and
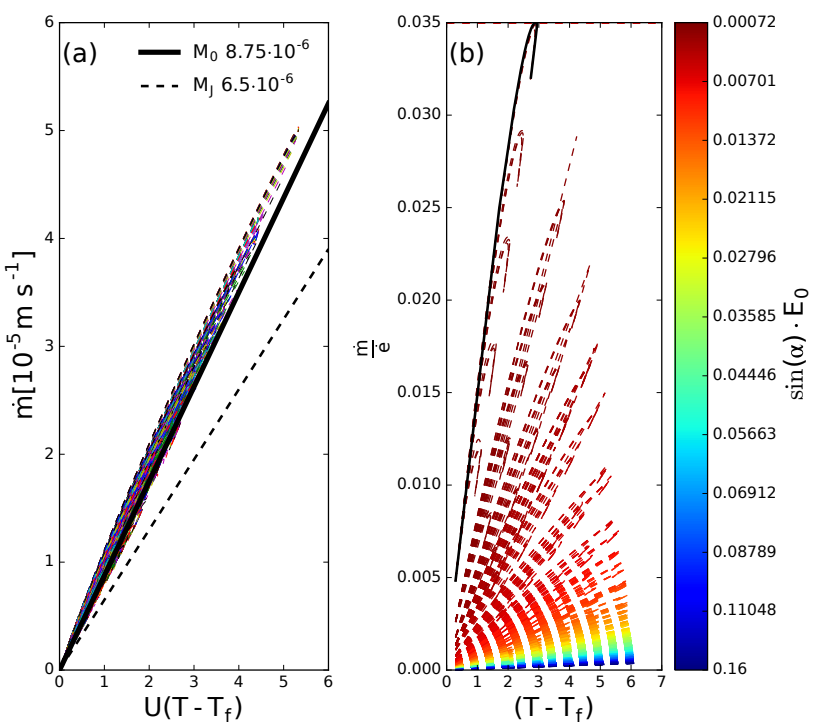

Figure A1. Investigation of melting proportion in the plume equations for different LP experiments. The plume model was run in a well-mixed environment for different parameter settings: $\left.E_{0}[0.036-0.16], \sin (\alpha)[0.02-1], q_{\mathrm{sg}}\left[10^{-5}-0.1 \mathrm{~m}^{2} \mathrm{~s}^{-1}\right], T_{\mathrm{a}}\right][0-$ $4{ }^{\circ} \mathrm{C}$. Panel (a) shows the melt rate as a function of plume velocity $U$ and plume temperature $T$ and its freezing temperature $T_{\mathrm{f}}\left(\dot{m}=M_{0}\left(T-T_{\mathrm{f}}\right) U\right)$. The average slope of the run is $M_{0} \approx$ $8.75 \times 10^{-6}$ (thick black line) while for the simplified equations of Jenkins (2011) a typical slope lies of the order of $6.5 \times 10^{-6}$ (black dashed line). The second panel illustrates that $\dot{m} \ll \dot{e}$ in this parameter range, but $\dot{m} / \dot{e}$ being largest for long floating tongues.

associated length scales for the our approximation of the LP model (i.e., Eqs. A1 and A2), by using the equation for the volume flux (Eq. 1) so that

$(q X)^{\prime}=q^{\prime} X+q X^{\prime}=(\dot{e}+\dot{m}) X+q X^{\prime}$,

where $q=D U$ (the volume flux) and $X$ can be either $T, S$ or $U$. The convergence value $X_{\star}$ can be obtained by solving the corresponding equation $(q X)^{\prime}=f$ (where $f$ is the righthand-side term, e.g., Eqs. 2, 3 or 4) with $X^{\prime}=0$. Moreover, when the right-hand side term is not or weakly dependent on $X$ (i.e., for $T$ and $S$, as will be detailed below), the equation is analogous to a first-order differential linear equation with convergence length scale $L_{X}=\frac{q}{q^{\prime}} \approx \frac{q}{\dot{e}}=\frac{D}{E_{0} \sin \alpha}$, i.e., with fast convergence near the grounding line, where plume thickness $D$ is small.

\section{A2.1 Balance temperature and salinity}

Temperature and salinity Eqs. (3) and (4) can be rewritten as an intuitive mixing law by merging in Eqs. (5) and (6):

$(q T)^{\prime}=\dot{e} T_{\mathrm{a}}+\dot{m} T_{\mathrm{m}}$,

$(q S)^{\prime}=\dot{e} S_{\mathrm{a}}$, 
where $T_{\mathrm{m}}$ is an effective meltwater temperature, derived from Eq. (5):

$$
T_{\mathrm{m}}=c_{\mathrm{i}} / c T_{\mathrm{i}}-L / c+T_{\mathrm{b}}\left(1-c_{\mathrm{i}} / c\right) \approx c_{\mathrm{i}} / c T_{\mathrm{i}}-L / c .
$$

Variations of boundary layer temperature $T_{\mathrm{b}}$ around $0{ }^{\circ} \mathrm{C}$ can be safely neglected compared to latent heat, so that we will treat $T_{\mathrm{m}}$ as a constant. If $T_{\mathrm{i}}=-10^{\circ} \mathrm{C}$, we have $T_{\mathrm{m}} \approx$ $-89^{\circ} \mathrm{C}$. Nevertheless, for completeness note that $T_{\mathrm{b}}$ can be expressed as a function of melt rate, plume and ice temperatures from Eq. (5). Using our simplified melt rate Eq. (A1) and given that $\dot{m} \ll C_{\mathrm{d}}^{\frac{1}{2}} \Gamma_{\mathrm{T}} U$ by 2 orders of magnitude, an accurate approximation for $T_{\mathrm{b}}$ is given by

$T_{\mathrm{b}}-T_{\mathrm{f}}=\left(1-\frac{c_{\mathrm{i}} M_{0}\left(L / c_{\mathrm{i}}-T_{\mathrm{i}}\right)}{c C_{\mathrm{d}}^{\frac{1}{2}} \Gamma_{\mathrm{T}}}\right) \Delta T \approx 0.1 \Delta T$,

where we verify that boundary layer temperature is somewhat closer to freezing temperature than to plume temperature. In the case of plume salinity $S_{\mathrm{b}}$ cancels out completely and $S_{\mathrm{i}}=0$ (as can be verified straightforwardly using Eqs. 4 and 6), so no other term is needed. By decomposing Eq. (A4) as outlined in Eq. (A3), and searching for solutions when $T^{\prime}=0$, with $\dot{m} \ll \dot{e}$, we obtain an expression for balance temperature:

$T_{\star} \approx T_{\mathrm{a}}+\frac{\dot{m}}{\dot{e}}\left(T_{\mathrm{m}}-T_{\mathrm{a}}\right)$,

which can be rearranged by using Eq. (A2) in "balance" regime, so that $\frac{\dot{m}}{\dot{e}} \approx\left(\frac{\dot{m}}{\dot{e}}\right)_{\star} \approx \frac{\Delta T_{\star}}{T_{\mathrm{e}}}$, and neglecting the secondorder $T_{\mathrm{a}} / T_{\mathrm{e}}$, into

$\Delta T_{\star} \approx \frac{\Delta T_{\mathrm{a}}}{1-T_{\mathrm{m}} / T_{\mathrm{e}}}$,

or equivalently

$$
\left(\frac{\dot{m}}{\dot{e}}\right)_{\star} \approx \frac{\Delta T_{\mathrm{a}}}{T_{\mathrm{e}}-T_{\mathrm{m}}} .
$$

The ratio $-T_{\mathrm{m}} / T_{\mathrm{e}}$ spans about $10^{-2}$ to 1 in our experiments, with a maximum of 0.02 for tidewater glaciers, i.e., $\Delta T_{\star} \approx$ $\Delta T_{\mathrm{a}}$. Here the freezing temperature implied by $\Delta$ should be taken for balance plume salinity, which is nearly the same as ambient salinity in first approximation (Eqs. A5, A2, A10):

$$
\begin{aligned}
S_{\star} & =\frac{\dot{e}}{\dot{e}+\dot{m}} S_{\mathrm{a}} \approx\left(1-\frac{\dot{m}}{\dot{e}}\right) S_{\mathrm{a}} \approx\left(1-\frac{\Delta T_{\mathrm{a}}}{T_{\mathrm{e}}-T_{\mathrm{m}}}\right) S_{\mathrm{a}} \\
& \approx S_{\mathrm{a}},
\end{aligned}
$$

so that $\Delta T_{\star} \approx T_{\star}-T_{\mathrm{fa}}$ and $\Delta T_{\mathrm{a}} \approx T_{\mathrm{a}}-T_{\mathrm{fa}}$, where $T_{\mathrm{fa}}$ is the freezing temperature for ambient salinity.

\section{A2.2 Balance velocity}

A similar reasoning as in the previous section (using Eq. A3 and $q^{\prime} \approx \dot{e}$ ), Eqs. (1) and (2) can be rearranged into an equation for $U^{2}$ (note the identity $\left(U^{2}\right)^{\prime}=2 U U^{\prime}$ ):

$\frac{1}{2}\left(U^{2}\right)^{\prime}+\frac{\left(C_{\mathrm{d}}+C_{\mathrm{e}}\right)}{D} U^{2}=b$,

where $b=\sin (\alpha) g \frac{\Delta \rho}{\rho_{0}}$ and $C_{\mathrm{e}}=E_{0} \sin \alpha$. This highlights in one equation basic plume dynamics, buoyancy-accelerated and balanced by drag and entrainment. Equation (A12) is analogous to a first-order linear differential equation with equilibrium solution for $x>>L_{u}$ :

$U_{\star}=\sqrt{\frac{b \cdot D}{C_{\mathrm{d}}+C_{\mathrm{e}}}}$

and length scale

$$
L_{u}=\frac{D}{2\left(C_{\mathrm{d}}+C_{\mathrm{e}}\right)} .
$$

Note that Eq. (A13) does not represent a strict equilibrium but a dynamic balance between velocity, plume thickness and buoyancy, which is maintained while the plume thickness and associated volume flux keeps increasing. Note that as the plume dimension increases due to entrainment (or for large discharge), so does the length scale $L_{u}$, and $U$ may lag behind $U_{\star}$. At $x=0$ for typical discharge and entrainment values $L_{u}$ is less than a centimeter. Our simulations show that velocity reaches dynamic balance $U_{\star}$ within the first few meters after the grounding line (not shown). This shows qualitative agreement with the above analysis but suggests that initial changes in plume dimension $D$ and buoyancy $b$ should be taken into account for more detailed analysis of the transient regime. In the present analysis we focus on the balance regime. The theoretical equilibration length scale for velocity is shorter than for temperature and salinity by a factor of 2 or more, since $L_{T S} / L_{U}=2\left(1+\frac{C_{\mathrm{d}}}{E_{0} \sin \alpha}\right)$, especially for long floating tongues. In the actual simulations the ratio is even larger, because the plume keeps growing with distance from its source.

The balance velocity is more conveniently expressed as a function of plume's volume flux $q$ instead of thickness $D$. By taking the square of Eq. (A13) and multiplying by $U_{\star}$, the identity $q \approx q_{\star}=D U_{\star}$ can be used, so that

$U_{\star}=\left(\frac{q \cdot b}{C_{\mathrm{d}}+C_{\mathrm{e}}}\right)^{\frac{1}{3}}$.

This new expression shows that velocity can be written as a power law of the buoyancy flux $q b$. Its initial condition is known, since $q=q_{\mathrm{sg}}$ and $b=b_{0}$ at $x=0$. The evolution of $q b$ as the plume develops can also conveniently be derived 
from Eqs. (A4) and (A5). For simplicity we limit the derivation to the case of a fjord without stratification $\left(T_{\mathrm{a}}^{\prime}=0\right.$ and $\left.S_{\mathrm{a}}^{\prime}=0\right)$, where

$(q b)^{\prime}=\dot{m} b_{\mathrm{m}}$,

where $b_{\mathrm{m}}=g \sin \alpha\left(\beta_{S} S_{\mathrm{a}}-\beta_{T}\left(T_{\mathrm{a}}-T_{\mathrm{m}}\right)\right)$ is the meltwater buoyancy minus the heat sink required to melt the ice. Note the temperature account for about $15 \%$ of buoyancy variations. According to Eq. (A1) the melt rate is proportional to $U$; thus in the regime where $U \approx U_{\star}$, we obtain a new differential equation for $U_{\star}^{\prime}$. By elevating Eq. (A15) at the third power and differentiating, we can use Eq. (A16) and the identity $\left(U^{2}\right)^{\prime}=2 U U^{\prime}$ to obtain

$$
\left(U_{\star}^{2}\right)^{\prime}=\frac{2}{3} \frac{b_{\mathrm{m}}}{C_{\mathrm{d}}+C_{\mathrm{e}}} M_{0} \Delta T .
$$

Equation (A17) shows that plume acceleration (in "balance" regime) does not depend on subglacial discharge. By integration,

$$
U_{\star}^{2}=U_{\star 0}^{2}+\int_{0}^{x}\left(U_{\star}^{2}\right)^{\prime} \mathrm{d} x \approx U_{\star 0}^{2}+\left(U_{\star}^{2}\right)^{\prime} x,
$$

where $U_{\star 0}$ is the balance velocity at $x=0$, given by Eq. (A15), and $\Delta T \approx \Delta T_{\star}$ in $\left(U_{\star}^{2}\right)^{\prime}$ and finally by replacing $\Delta T_{\star}$ with Eq. (A9), we obtain

$U_{\star}(x) \approx \sqrt{\left(\frac{q_{\mathrm{sg}} \cdot b_{0}}{C_{\mathrm{d}}+C_{\mathrm{e}}}\right)^{\frac{2}{3}}+\frac{2}{3} \frac{b_{\mathrm{m}}}{C_{\mathrm{d}}+C_{\mathrm{e}}} \frac{M_{0} \Delta T_{\mathrm{a}}}{1-M_{0} T_{\mathrm{m}} / C_{\mathrm{e}}} x}$,

where $b_{0}=g \sin \alpha\left(\beta_{S} S_{\mathrm{a}}-\beta_{T} T_{\mathrm{a}}\right)$ is the buoyancy at $x=0$ (equal to meltwater buoyancy). From Eq. (A19) it follows that along the glacier front, the plume velocity remains constant for high discharges but accelerates for small discharges, as depicted in Fig. A2. The evolution of the plume velocity, temperature and melt rate for high and low entertainment coefficients and discharges on tidewater glaciers and glaciers with long floating tongues is depicted in Fig. A3 with the corresponding balance approximation (Eq. A1). See Table A1 for a summary of the variables defined in the Appendix (note we already wrote $T_{\mathrm{e}}$ in full to see the effect of entrainment more explicitly).

\section{A2.3 Cumulative melt rate}

With Eqs. (A1), (A9), (A17) and (A19), we can now derive an expression for the cumulative melt rate in the LP model, as

$$
M_{\star}(x)=\int_{0}^{x} \dot{m} \mathrm{~d} x \approx M_{0} \Delta T_{\star} \int_{0}^{x} U_{\star}(x) \mathrm{d} x
$$

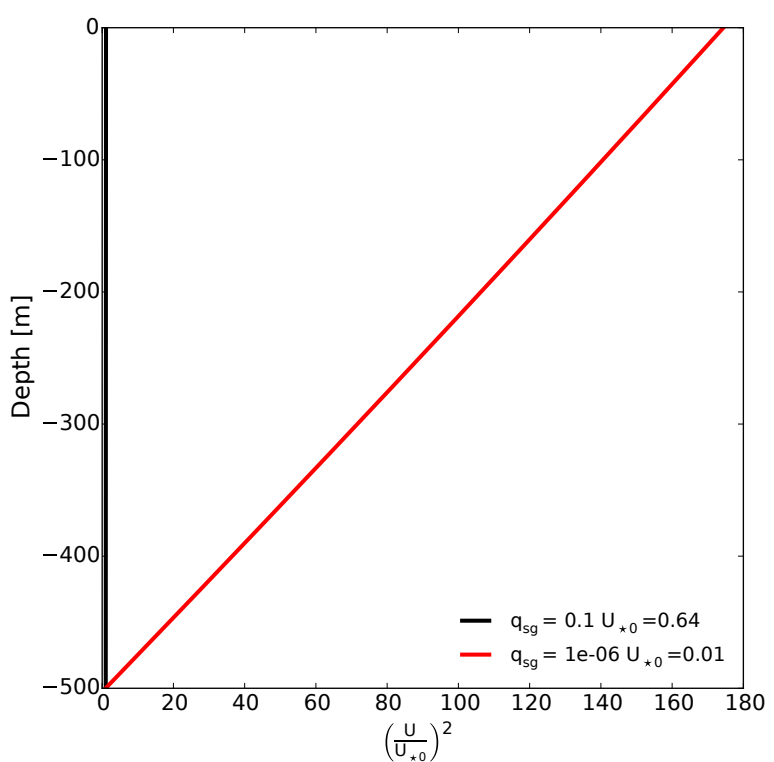

Figure A2. Evolution of $U$ for an initial velocity of $U_{\star}$. The plume with a small discharge $\left(q_{\mathrm{sg}}=10^{-6} \mathrm{~m}^{2} \mathrm{~s}^{-1}\right)$ will accelerate strongly (red line, $U_{\star}=0.14 \mathrm{~m} \mathrm{~s}^{-1}$ ) while the plume velocity with larger discharge remains almost constant (black line, $q_{\mathrm{sg}}=0.1 \mathrm{~m}^{2} \mathrm{~s}^{-1}$, $U_{\star}=0.63 \mathrm{~m} \mathrm{~s}^{-1}$ ).
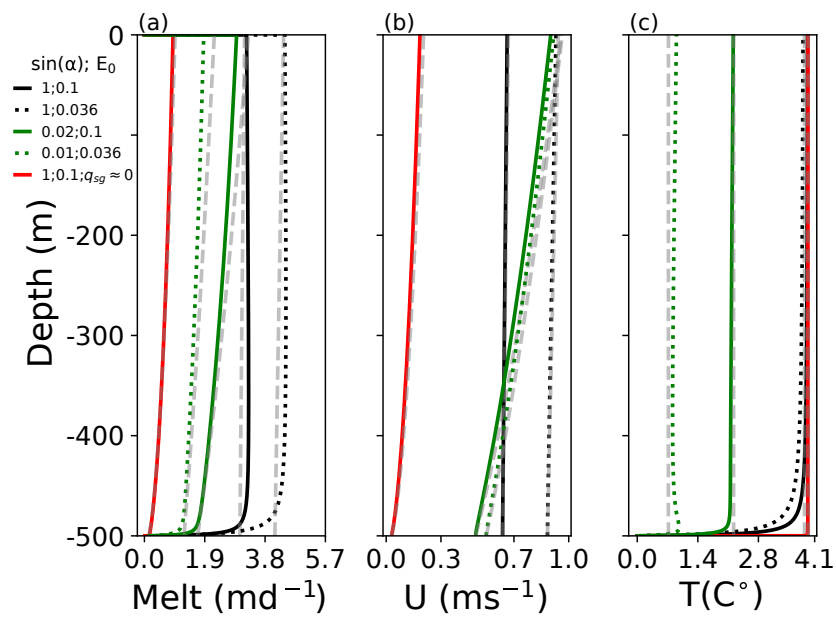

Figure A3. Evolution of $m$ (a), $U$ (b) and $T$ (c) along $Z$ for the tidewater glaciers with high discharge $\left(q_{\mathrm{sg}}=0.1 \mathrm{~m}^{2} \mathrm{~s}^{-1}\right.$, black line $)$, low discharge $\left(q_{\mathrm{sg}}=10^{-5} \mathrm{~m}^{2} \mathrm{~s}^{-1}\right.$, red line $)$ and a floating tongue glacier $\left(q_{\mathrm{sg}}=0.1 \mathrm{~m}^{2} \mathrm{~s}^{-1}\right.$, green line $)$. Solid lines indicate plumes with $E_{0}=0.1$ while dotted lines represent plume with $E_{0}=0.036$. The corresponding "balance" approximations $m_{\star}=M_{0} U_{\star} \Delta T_{\star}, U_{\star}$ and $T_{\star}$ are overlaid as grey dashed lines. 
Table A1. Summary of Appendix variables. Illustrative value provided for $T_{\mathrm{i}}=-10^{\circ} \mathrm{C}, T_{\mathrm{a}}=4{ }^{\circ} \mathrm{C}, S_{\mathrm{a}}=34.65 \mathrm{psu}$, sin $\alpha=1$ (tidewater glacier) and range for $E_{0}=0.036-0.16$.

\begin{tabular}{lllr}
\hline Symbol & Definition & Interpretation & Illustrative value \\
\hline$M_{0}$ & - & melt rate coefficient in Eq. (A1) & $8.2 \times 10^{-6 \circ{ }^{\circ} \mathrm{C}^{-1}}$ \\
$b_{0}$ & $g \sin \alpha\left(\beta_{S} S_{\mathrm{a}}-\beta_{T} T_{\mathrm{a}}\right)$ & buoyancy at $x=0$ & $0.27 \mathrm{~m} \mathrm{~s}^{-2}$ \\
$b_{\mathrm{m}}$ & $g \sin \alpha\left(\beta_{S} S_{\mathrm{a}}-\beta_{T}\left(T_{\mathrm{a}}-T_{\mathrm{m}}\right)\right)$ & buoyancy source term due to melting & $0.23 \mathrm{~m} \mathrm{~s}^{-2}$ \\
$T_{\mathrm{m}}$ & $c_{\mathrm{i}} / c T_{\mathrm{i}}-L / c$ & effective meltwater temperature & $-0.9 \times 10^{2}{ }^{\circ} \mathrm{C}$ \\
$T_{\mathrm{e}}$ & $E_{0} \sin \alpha$ & entrainment-equivalent temperature & $4.4 \times 10^{3}-2.0 \times 10^{4}{ }^{\circ} \mathrm{C}$ \\
$C_{\mathrm{e}}$ & $E_{0} \sin \alpha$ & effective entrainment & $0.036-0.16$ \\
$\Delta T_{\mathrm{a}}$ & $T_{\mathrm{a}}-T_{\mathrm{f}}\left(S_{\mathrm{a}}\right)$ & ambient temperature above freezing & $\approx 6{ }^{\circ} \mathrm{C}$ \\
\hline
\end{tabular}

$$
= \begin{cases}M_{0} \Delta T_{\star} U_{\star 0} x, & \text { if } U_{\star}^{\prime} \approx 0 \\ \frac{C_{\mathrm{d}}+C_{\mathrm{e}}}{b_{\mathrm{m}}}\left(U_{\star}^{3}(x)-U_{\star 0}^{3}\right), & \text { if } U_{\star}^{\prime}>0 .\end{cases}
$$

We used the fact that if $U=(A+B x)^{1 / 2}$, where $A$ and $B$ are constant (Eq. A19), a primitive $\int U$ is $\frac{2}{3 B}(A+B x)^{3 / 2}=$ $\frac{2}{3 B} U^{3}$, provided that $B \neq 0$, i.e., that $U_{\star}^{\prime} \neq 0$; additionally since $B=\left(U_{\star}^{2}\right)^{\prime}$ is proportional to $\frac{2}{3} M_{0} \Delta T_{\star}$ (Eq. A17), these terms cancel out.

The error of Eq. (A20) compared to the cumulative melt rate of the LP model in the unstratified case for tidewater glaciers was $2 \%$ for large discharge $\left(q=0.1 \mathrm{~m}^{2} \mathrm{~s}^{-1}\right)$ and $9 \%$ for small discharge $\left(q=1 \cdot 10^{-} 6 \mathrm{~m}^{2} \mathrm{~s}^{-1}\right)$. For the case of a long floating tongue and a discharge of $q=0.1 \mathrm{~m}^{2} \mathrm{~s}^{-1}$ the error was in the range of $10 \%$.

We can identify two limiting cases for Eq. (A20), characterized by discharge-driven $\left(U_{\star}^{\prime} \approx 0\right.$, i.e., large discharge $\left.M_{\text {high }}\right)$ or melt-driven $\left(U_{\star 0} \approx 0\right.$, i.e., small discharge $\left.M_{\text {low }}\right)$ convection (see also Eqs. A18 and A19). Let us define $L$ as the full length of the plume (note that it is related to grounding line depth $Z=L \sin \alpha$ ). We have

$M_{\text {high }} \approx\left(\frac{b_{0} q_{\mathrm{sg}}}{C_{\mathrm{d}}+C_{\mathrm{e}}}\right)^{\frac{1}{3}}\left(\frac{M_{0} \Delta T_{\mathrm{a}}}{1-M_{0} T_{\mathrm{m}} / C_{\mathrm{e}}} L\right)$,

discharge-driven, $q_{\mathrm{sg}} \gg q_{\mathrm{c}}$,

$M_{\text {low }} \approx\left(\frac{b_{\mathrm{m}}}{C_{\mathrm{d}}+C_{\mathrm{e}}}\right)^{\frac{1}{2}}\left(\frac{2}{3} \frac{M_{0} \Delta T_{\mathrm{a}}}{1-M_{0} T_{\mathrm{m}} / C_{\mathrm{e}}} L\right)^{\frac{3}{2}}$,

melt-driven, $q_{\mathrm{sg}} \ll q_{\mathrm{c}}$, where the critical discharge $q_{\mathrm{c}}$ is defined as the discharge for which $M_{\text {high }}=M_{\text {low }}$, equal to

$q_{\mathrm{c}}=\left(\frac{2}{3}\right)^{\frac{9}{2}} \frac{b_{\mathrm{m}}^{\frac{3}{2}}}{b_{0}\left(C_{\mathrm{d}}+C_{\mathrm{e}}\right)^{\frac{1}{2}}}\left(\frac{M_{0} \Delta T_{\mathrm{a}}}{1-M_{0} T_{\mathrm{m}} / C_{\mathrm{e}}} L\right)^{\frac{3}{2}}$.

For a tidewater glacier $q_{\mathrm{c}}$ is of the order of $10^{-3} \mathrm{~m}^{3} \mathrm{~s}^{-1}$, and can reach $10^{-1} \mathrm{~m}^{3} \mathrm{~s}^{-1}$ for a few tens of kilometers of floating tongue. This indicates that in glaciers with a floating tongue, melt-driven convection tends to be more important than in tidewater glaciers.

We also note from Eqs. (A21) and (A22) that the dependence of melt rate on entrainment coefficient $C_{\mathrm{e}}$ (which contains both entrainment parameter $E_{0}$ and glacier slope $\sin \alpha)$ is not monotonic. For moderately large values of $C_{\mathrm{e}}$ $\left(-M_{0} T_{\mathrm{m}} / C_{\mathrm{e}} \ll 1\right.$, e.g., tidewater glaciers), variations in the left-hand-side factor ("dynamics") dominate and the melt rate is a decreasing function of, but moderately sensitive to, $C_{\mathrm{e}}$. However, for small $C_{\mathrm{e}}$ values $\left(-M_{0} T_{\mathrm{m}} / C_{\mathrm{e}} \sim 1\right.$ and thus $C_{\mathrm{e}} \ll C_{\mathrm{d}}$, i.e., long floating tongue), where variations in the right-hand-side factor ("thermodynamics") dominate, the melt rate is an increasing function of $C_{\mathrm{e}}$. For the lowest entrainment value $E_{0}=0.036$, "small" means a glacier front angle of the order of $\sin \alpha=0.02$. 


\section{The Supplement related to this article is available online at https://doi.org/10.5194/tc-12-301-2018-supplement.}

Author contributions. and AG designed the study and conducted the analysis. JB implemented the numerical models and performed the experiments. MP and JB derived the analytical solutions. JB prepared the manuscript with contribution from all authors.

Competing interests. The authors declare that they have no conflict of interest.

Acknowledgements. This work was funded by LeibnizGemeinschaft, WGL Pakt für Forschung SAW-2014-PIK-1. We thank David Sutherland for the CTD data of Kangerlussuup Sermia, Fiamma Stranero and Dustin Carroll for the CTD measurement data of Helheim, and Donald Slater for providing us with the data of his experiment. Furthermore we thank Adrian Jenkins for providing us with his plume code to compare our simulated melt rate profiles among the models. Thanks to Reinhard Calov for support in numerical procedures.

Edited by: G. Hilmar Gudmundsson

Reviewed by: four anonymous referees

\section{References}

Andersen, M. L., Larsen, T. B., Nettles, M., Elosegui, P., Van As, D., Hamilton, G. S., Stearns, L. A., Davis, J. L., Ahlstrm, A. P., De Juan, J., Ekstrm, G., Stenseng, L., Khan, S. A., Forsberg, R., and Dahl-Jensen, D.: Spatial and temporal melt variability at Helheim Glacier, East Greenland, and its effect on ice dynamics, J. Geophys. Res.-Earth, 115, 1-18, https://doi.org/10.1029/2010JF001760, 2010.

Bartholomaus, T. C., Stearns, L. A., Sutherland, D. A., Shroyer, E. L., Nash, J. D., Walker, R. T., Catania, G., Felikson, D., Carroll, D., Fried, M. J., Noël, B. P. Y., and Van Den Broeke, M. R.: Contrasts in the response of adjacent fjords and glaciers to icesheet surface melt in West Greenland, Ann. Glaciol., 57, 1-14, https://doi.org/10.1017/aog.2016.19, 2016.

Bindschadler, R. A., Nowicki, S., Abe-OUCHI, A., Aschwanden, A., Choi, H., Fastook, J., Granzow, G., Greve, R., Gutowski, G., Herzfeld, U., Jackson, C., Johnson, J., Khroulev, C., Levermann, A., Lipscomb, W. H., Martin, M. A., Morlighem, M., Parizek, B. R., Pollard, D., Price, S. F., Ren, D., Saito, F., Sato, T., Seddik, H., Seroussi, H., Takahashi, K., Walker, R., and Wang, W. L.: Icesheet model sensitivities to environmental forcing and their use in projecting future sea level (the SeaRISE project), J. Glaciol., 59, 195-224, https://doi.org/10.3189/2013JoG12J125, 2013.

Carr, J. R., Vieli, A., Stokes, C. R., Jamieson, S. S. R., Palmer, S. J., Christoffersen, P., Dowdeswell, J. A., Nick, F. M., Blankenship, D. D., and Young, D. A.: Basal topographic controls on rapid retreat of Humboldt Glacier, northern Greenland, J. Glaciol., 61, 137-150, https://doi.org/10.3189/2015JoG14J128, 2015.
Carroll, D., Sutherland, D. A., Shroyer, E. L., Nash, J. D., Catania, G. A., and Stearns, L. A.: Modeling Turbulent Subglacial Meltwater Plumes: Implications for Fjord-Scale Buoyancy-Driven Circulation, J. Phys. Oceanogr., 45, 2169 2185, https://doi.org/10.1175/JPO-D-15-0033.1, 2015.

Carroll, D., Sutherland, D. A., Hudson, B., Moon, T., Catania, G. A., Shroyer, E. L., Nash, J. D., Bartholomaus, T. C., Felikson, D., Stearns, L. A., Noël, B. P. Y., and van den Broeke, M. R.: The impact of glacier geometry on meltwater plume structure and submarine melt in Greenland fjords, Geophys. Res. Lett., 43, 1-10, https://doi.org/10.1002/2016GL070170, 2016.

Chauche, N.: Glacier-Ocean interaction at Store Glacier (West Greenland), Aberystwyth University, available at: http://hdl. handle.net/2160/42621 (last access: 25 January 2018), 2016.

Church, J. A. and White, N. J.: Sea-Level Rise from the Late 19th to the Early 21st Century, Surv. Geophys., 32, 585-602, https://doi.org/10.1007/s10712-011-9119-1, 2011.

Church, J. A., Clark, P. U., Cazenave, A., Gregory, J. M., Jevrejeva, S., Levermann, A., Merrifield, M. A., Milne, G. A., Nerem, R. S., Nunn, P. D., Payne, A. J., Pfeffer, W. T., Stammer, D., and Unnikrishnan, A. S.: Sea Level Change, in: Climate Change 2013: The Physical Science Basis. Contribution of Working Group I to the Fifth Assessment Report of the Intergovernmental Panel on Climate Change, edited by: Stocker, T. F., Qin, D., Plattner, G.K., Tignor, M., Allen, S. K., Boschung, J., Nauels, A., Xia, Y., Bex, V., and Midgley, P. M., Cambridge University Press, Cambridge, UK and New York, NY, USA, 2013.

Cowton, T., Slater, D., Sole, A., Goldberg, D., and Nienow, P.: Modeling the impact of glacial runoff on fjord circulation and submarine melt rate using a new subgrid-scale parameterization for glacial plumes, J. Geophys. Res.-Oceans, 120, 796-812, https://doi.org/10.1002/2014JC010324, 2015.

Dallaston, M. C., Hewitt, I. J., and Wells, A. J.: Channelization of plumes beneath ice shelves, J. Fluid Mech., 785, 109-134, https://doi.org/10.1017/jfm.2015.609, 2015.

Fried, M. J., Catania, G. A., Bartholomaus, T. C., Duncan, D., Davis, M., Stearns, L. A., Nash, J., Shroyer, E., and Sutherland, D.: Distributed subglacial discharge drives significant submarine melt at a Greenland tidewater glacier, Geophys. Res. Lett., 42, 9328-9336, https://doi.org/10.1002/2015GL065806, 2015.

Fürst, J. J., Goelzer, H., and Huybrechts, P.: Ice-dynamic projections of the Greenland ice sheet in response to atmospheric and oceanic warming, The Cryosphere, 9, 1039-1062, https://doi.org/10.5194/tc-9-1039-2015, 2015.

Gade, H. G.: Melting of ice in Sea Water: A primitive Model with Application to the Antartic Iceshelf and Icebergs, J. Phys. Oceanogr., 9, 189-198, 1979.

Gladish, C. V., Holland, D. M., Holland, P. R., and Price, S. F.: Iceshelf basal channels in a coupled ice/ocean model, J. Glaciol., 58, 1227-1244, https://doi.org/10.3189/2012JoG12J003, 2012.

Holland, D. M., Thomas, R. H., de Young, B., Ribergaard, M. H., and Lyberth, B.: Acceleration of Jakobshavn Isbræ triggered by warm subsurface ocean waters, Nat. Geosci., 1, 659-664, https://doi.org/10.1038/ngeo316, 2008.

Holland, P. R., Jenkins, A., and Holland, D. M.: The Response of Ice Shelf Basal Melting to Variations in Ocean Temperature, J. Climate, 21, 2558-2572, https://doi.org/10.1175/2007JCLI1909.1, 2007. 
Jackson, R. H. and Straneo, F.: Heat, Salt, and Freshwater Budgets for a Glacial Fjord in Greenland, J. Phys. Oceanogr., 46, 27352768, https://doi.org/10.1175/JPO-D-15-0134.1, 2016.

Jackson, R. H., Straneo, F., and Sutherland, D. A.: Externally forced fluctuations in ocean temperature at Greenland glaciers in non-summer months, Nat. Geosci., 7, 503-508, https://doi.org/10.1038/ngeo2186, 2014.

Jenkins, A.: A one-dimensional model of ice shelf-ocean interaction, J. Geophys. Res.-Oceans, 96, 671-677, 1991.

Jenkins, A.: Convection-Driven Melting near the Grounding Lines of Ice Shelves and Tidewater Glaciers, J. Phys. Oceanogr., 41, 2279-2294, https://doi.org/10.1175/JPO-D-11-03.1, 2011.

Johnson, H. L., Münchow, A., Falkner, K. K., and Melling, H.: Ocean circulation and properties in Petermann Fjord, Greenland, J. Geophys. Res., 116, C01003, https://doi.org/10.1029/2010JC006519, 2011.

Kaye, N. B. and Linden, P. F.: Coalescing axisymmetric turbulent plumes, J. Fluid Mech., 502, 41-63, https://doi.org/10.1017/S0022112003007250, 2004.

Khan, S. A., Kjaer, K. H., Bevis, M., Bamber, J. L., Wahr, J., Kjeldsen, K. K., Bjork, A. A., Korsgaard, N. J., Stearns, L. A., van den Broeke, M. R., Liu, L., Larsen, N. K., and Muresan, I. S.: Sustained mass loss of the northeast Greenland ice sheet triggered by regional warming, Nat. Clim. Change, 4, 292-299, https://doi.org/10.1038/nclimate2161, 2014.

Kimura, S., Holland, P. R., Jenkins, A., and Piggott, M.: The Effect of Meltwater Plumes on the Melting of a Vertical Glacier Face, J. Phys. Oceanogr., 44, 3099-3117, https://doi.org/10.1175/JPOD-13-0219.1, 2014.

Lea, J. M., Mair, D. W. F., Nick, F. M., Rea, B. R., van As, D., Morlighem, M., Nienow, P. W., and Weidick, A.: Fluctuations of a Greenlandic tidewater glacier driven by changes in atmospheric forcing: observations and modelling of Kangiata Nunaata Sermia, 1859-present, The Cryosphere, 8, 2031-2045, https://doi.org/10.5194/tc-8-2031-2014, 2014.

Linden, P. F., Lane-Serff, G. F., and Smeed, D. A.: Emptying filling boxes: the fluid mechanics of natural ventilation, J. Fluid Mech., 212, 309-335, https://doi.org/10.1017/S0022112090001987, 1990.

Little, C. M., Gnanadesikan, A., and Oppenheimer, M.: How ice shelf morphology controls basal melting, J. Geophys. Res., 114, C12007, https://doi.org/10.1029/2008JC005197, 2009.

Magorrian, S. J. and Wells, A. J.: Turbulent plumes from a glacier terminus melting in a stratified ocean, J. Geophys. Res.-Oceans, 121, 4670-4696, https://doi.org/10.1002/2015JC011160, 2016.

McConnochie, C. D. and Kerr, R. C.: The turbulent wall plume from a vertically distributed source of buoyancy, J. Fluid Mech., 787, 237-253, https://doi.org/10.1017/jfm.2015.691, 2016.

Morlighem, M., Rignot, E., Mouginot, J., Seroussi, H., and Larour, E.: Deeply incised submarine glacial valleys beneath the Greenland ice sheet, Nat. Geosci., 7, 418-422, https://doi.org/10.1038/ngeo2167, 2014.

Morton, B. R., Taylor, G., and Turner, J. S.: Turbulent Gravitational Convection from Maintained and Instantaneous Sources, P. Roy. Soc. A-Math. Phy., 234, 1-23, https://doi.org/10.1098/rspa.1956.0011, 1956.

Motyka, R. J., Hunter, L., Echelmeyer, K. A., and Connor, C.: Submarine melting at the terminus of a temperate tidewater glacier, LeConte Glacier, Alaska, USA, Ann. Glaciol., 36, 5765, https://doi.org/10.3189/172756403781816374, 2003.

Motyka, R. J., Dryer, W. P., Amundson, J., Truffer, M., and Fahnestock, M.: Rapid submarine melting driven by subglacial discharge, LeConte Glacier, Alaska, Geophys. Res. Lett., 40, $5153-$ 5158, https://doi.org/10.1002/grl.51011, 2013.

Mugford, R. I. and Dowdeswell, J. A.: Modeling glacial meltwater plume dynamics and sedimentation in highlatitude fjords, J. Geophys. Res.-Earth, 116, 1-20, https://doi.org/10.1029/2010JF001735, 2011.

Nick, F. M., Luckman, A., Vieli, A., Van Der Veen, C. J., Van As, D., Van De Wal, R. S. W., Pattyn, F., Hubbard, A. L., and Floricioiu, D.: The response of Petermann Glacier, Greenland, to large calving events, and its future stability in the context of atmospheric and oceanic warming, J. Glaciol., 58, 229-239, https://doi.org/10.3189/2012JoG11J242, 2012.

Nick, F. M., Vieli, A., Andersen, M. L., Joughin, I., Payne, A., Edwards, T. L., Pattyn, F., and van de Wal, R. S. W.: Future sea-level rise from Greenland's main outlet glaciers in a warming climate, Nature, 497, 235-238, https://doi.org/10.1038/nature12068, 2013.

Rignot, E. and Kanagaratnam, P.: Changes in the Velocity Structure of the Greenland Ice Sheet, Science, 311, 986-990, https://doi.org/10.1126/science.1121381, 2006.

Rignot, E. and Steffen, K.: Channelized bottom melting and stability of floating ice shelves, Geophys. Res. Lett., 35, L02503, https://doi.org/10.1029/2007GL031765, 2008.

Rignot, E., Koppes, M., and Velicogna, I.: Rapid submarine melting of the calving faces of West Greenland glaciers, Nat. Geosci., 3, 187-191, https://doi.org/10.1038/ngeo765, 2010.

Rignot, E., Fenty, I., Xu, Y., Cai, C., and Kemp, C.: Undercutting of marine-terminating glaciers in West Greenland, Geophys. Res. Lett., 42, 5909-5917, https://doi.org/10.1002/2015GL064236, 2015.

Schoof, C.: Ice-sheet acceleration driven by melt supply variability, Nature, 468, 803-806, https://doi.org/10.1038/nature09618, 2010.

Sciascia, R., Straneo, F., Cenedese, C., and Heimbach, P.: Seasonal variability of submarine melt rate and circulation in an East Greenland fjord, J. Geophys. Res.-Oceans, 118, 2492-2506, https://doi.org/10.1002/jgrc.20142, 2013.

Slater, D. A., Nienow, P. W., Cowton, T. R., Goldberg, D. N., and Sole, A. J.: Effect of near-terminus subglacial hydrology on tidewater glacier submarine melt rates, Geophys. Res. Lett., 42, 2861-2868, https://doi.org/10.1002/2014GL062494, 2015.

Slater, D. A., Goldberg, D. N., Nienow, P. W., and Cowton, T. R.: Scalings for Submarine Melting at Tidewater Glaciers from Buoyant Plume Theory, J. Phys. Oceanogr., 46, 1839-1855, https://doi.org/10.1175/JPO-D-15-0132.1, 2016.

Sole, A. J., Mair, D. W. F., Nienow, P. W., Bartholomew, I. D., King, M. A., Burke, M. J., and Joughin, I.: Seasonal speedup of a Greenland marine-terminating outlet glacier forced by surface melt-induced changes in subglacial hydrology, J. Geophys. Res.Earth, 116, 1-11, https://doi.org/10.1029/2010JF001948, 2011.

Stevens, L. A., Straneo, F., Das, S. B., Plueddemann, A. J., Kukulya, A. L., and Morlighem, M.: Linking glacially modified waters to catchment-scale subglacial discharge using autonomous underwater vehicle observations, The Cryosphere, 10, 417-432, https://doi.org/10.5194/tc-10-417-2016, 2016. 
Straneo, F. and Cenedese, C.: The Dynamics of Greenland's Glacial Fjords and Their Role in Climate, Annu. Rev. Mar. Sci., 7, 89-112, https://doi.org/10.1146/annurev-marine-010213$135133,2015$.

Straneo, F. and Heimbach, P.: North Atlantic warming and the retreat of Greenland's outlet glaciers, Nature, 504, 36-43, https://doi.org/10.1038/nature12854, 2013.

Straneo, F., Curry, R. G., Sutherland, D. A., Hamilton, G. S., Cenedese, C., Våge, K., and Stearns, L. A.: Impact of fjord dynamics and glacial runoff on the circulation near Helheim Glacier, Nat. Geosci., 4, 322-327, https://doi.org/10.1038/ngeo1109, 2011.

Straneo, F., Sutherland, D. A., Holland, D., Gladish, C., Hamilton, G. S., Johnson, H. L., Rignot, E., Xu, Y., and Koppes, M.: Characteristics of ocean waters reaching greenland's glaciers, Ann. Glaciol., 53, 202-210, https://doi.org/10.3189/2012AoG60A059, 2012.
Sutherland, D. A. and Straneo, F.: Estimating ocean heat transports and submarine melt rates in sermilik fjord, greenland, using lowered acoustic doppler current profiler (LADCP) velocity profiles, Ann. Glaciol., 53, 50-58, https://doi.org/10.3189/2012AoG60A050, 2012.

Turner, J.: Buoyancy effects in fluids, Cambridge University Press, London, UK, 1973.

$\mathrm{Xu}$, Y., Rignot, E., Menemenlis, D., and Koppes, M.: Numerical experiments on subaqueous melting of Greenland tidewater glaciers in response to ocean warming and enhanced subglacial discharge, Ann. Glaciol., 53, 229-234, https://doi.org/10.3189/2012AoG60A139, 2012.

$\mathrm{Xu}$, Y., Rignot, E., Fenty, I., Menemenlis, D., and Flexas, M. M.: Subaqueous melting of Store Glacier, west Greenland from three-dimensional, high-resolution numerical modeling and ocean observations, Geophys. Res. Lett., 40, 4648-4653, https://doi.org/10.1002/grl.50825, 2013. 